\title{
Satellite Power System (SPS) International Agreements
}

October 1978

Prepared for:

U.S. Department of Energy Office of Energy Research

Satellite Power System Project Office

Under Contract No. EG-77-C-01-4024

\section{DOE/NASA}

Satellite Power System

Concept Development

and

Evaluation Program 


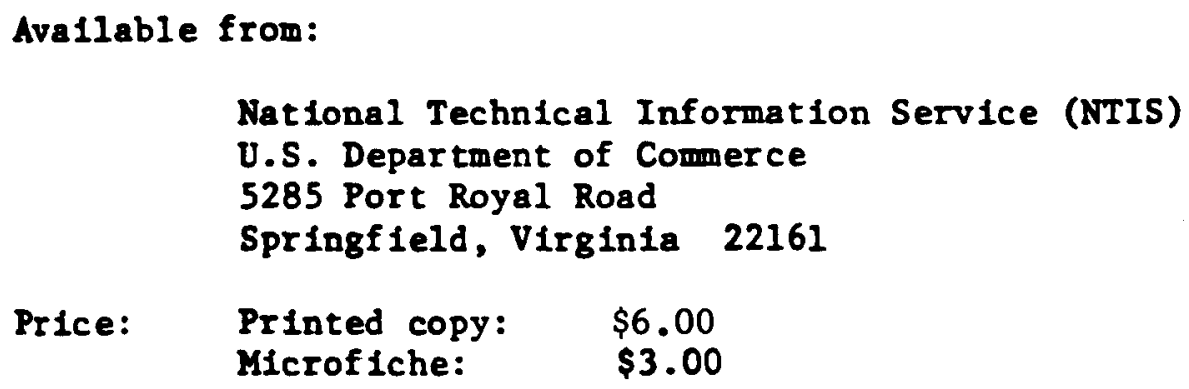




\section{Satellite Power System (SPS) International Agreements}

October 1978

Prepared by:

Stephen Grove

PRC Energy Analysis Company

McLean, Virginia 22102

Prepared for:

U.S. Department of Energy

Office of Energy Research

Satellite Power System Project Office

Washington, D.C. 20545

Under Contract No. EG-77-C-01-4024

\section{DOE/NASA}

Satellite Power System

Concept Development

and

Evaluation Program 


\section{NOTICE}

This report was prepared as an account of work sponsored by the United States Government. Neither the United States nor the United States Department of Energy, nor any of their employees, makes any warranty, express or implied, or assumes any legal liability or responsibility for the accuracy, completeness, or usefulness of any information, apparatus, product, or process disclosed, or represents that its use would not infringe privately owned rights. Reference herein to any specific commercial product, process, or service by trede name, mark, manufacturer, or otherwise, does not necessarily constitute or imply its endorsement, recommendation, or favoring by the United States Government or any agency thereof. The views and opinions of authors expressed herein do not necessarily state or reflect those of the United States Government or any egency thereof. 


\section{Acknowledgment}

Special thanks are due for the courtesies received from the Department of Energy, the Outer Space Affairs Division of the United Nations Secretariat and the PRC Systems Sciences Co. for providing research materials which were not readily available for general distribution. Similar gratitude is owed to ITU officials who generously gave their time for unofficial interviews in connection with this study. The following people reviewed the draft of this paper:

Harold Berger

Attorney

1622 Locust Street

Philadelphia, Pa. 19103

Leonard David

Program Director

Forum for the Advancement of Students in Science and Technology 2030 M. Street, N.W.

Washington, D.C. 20036

Paul Dembling

General Counsel

U.S. General Accounting office

Washington, D.C. 20548

James J. Gehrig

Counsel for the Senate committee on Science and Technology Washington, D.C. 20510 


\section{Executive Summary}

This study identifies the problems in obtaining international agreements on geostationary orbit availability, microwave frequency allocations and microwave frequency standards for satellites transmitting solar power. Its findings and recommendations are based on relevant literature, official documents and their interpretation, as well as on an evaluation of recent trends in the world community.

With respect to geostationary orbit availability the paper reviews applicable provisions of international space law, the Bogota Declaration and arguments pro and con. It finds the claims of equatorial countries legally and scientifically untenable but notes a fairly substantial support in the Legal subcommittee of the United Nations Committee on the Peaceful Uses of Outer Space for equity and fairness in consideration of the development of legal principles governing the use of geostationary orbit within the framework of the Outer space Treaty.

A review of International Telecommunication Union (ITU) related instruments indicates that while the 'first come, first served'principle regarding the use of geostationary orbit has remained basically unaltered from a strictly legal point of view, the key issue will be how to translate what the ITU calls -- the 'efficient and economic use' and 'equitable access' into more specific legal and technical principles and rules relating to the geostationary orbit for -- what the Outer space Treaty calls -- the "benefit and interests" of all countries.

Insofar as frequency for microwave power transmission is concerned, the most crucial issue pertaining to ITU is whether it would have competence to deal with such transmission. This in turn may depend on definition of power transmission by microwaves from space and interpretation of the word 'telecommunication'. The problem is complicated further by the inseparability of geostationary orbital positions and coordination of the use of radio spectrum to avoid harmful interference.

Perhaps the most important key issue is whether the United States should internationalize the SPS. With respect to key issues the various U.S. policy options, strategies and time frames are analyzed.

The paper concludes with recommendations for further short- and long-term studies. 


\section{List of Abbreviations}

CCIR - International Radio Consultative Committee

ESA - European Space Agency

GEOSAT - Geostationary satellite

ICAO - International Civil Aviation Organization

IAEA - International Atomic Energy Agency

IFRB - International Frequency Registration Board

IMCO - International Maritime Consultative Organization

INMARSAT - International Maritime Satellite Organization

INTELSAT - International Telecommunication Satellite Organization

ITC - International Telecommunication Convention, MalagaTorremolinos, Oct. 25, 1973.

ITU - International Telecommunication Union

SPS - Satellite Power System

UINCOPUOS - United Nations Committee on the Peaceful Uses of Outer Space

UNESCO - United Nations Educational Scientific and Cultural Organization

WARC-BS - World Administrative Radio Conference for the Planning of the Broadcasting-Satellite Service in Frequency Bands 11.7-12.2 GHz (in Regions 2 and 3 ) and 11.7-12.5 $\mathrm{GHz}$ (in Region 1), Geneva, 1977

WARC-ST - World Administrative Radio Conference for Space Telecommunications, Geneva, 1971

WHO - World Health Organization

WMO - World Meteorological Organization 
Acknowledgment . . . . . . . . . . . . . . . iii

Executive Summary • . . . . . . . • . . . . . . . v v

List of Abbreviations . . . . . . . . . . . . . . vii

1. INTRODUCTION . • . . . . . . . . . . . . . . . . 1

1.1 Background . . . . . . . . . . . . . . . . . . 1

1.2 Objectives and Tasks . . . . . . . . . . . . . 1

1.3 Assumptions . . . . . . . . . . . . . . . 2

1.4 Methodology . . . . . . . . . . . . . . . . 3

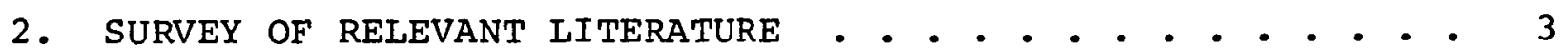

2.1 General Background Materials . . . . . . . . . 3

2.2 Specialized Materials . . . . . . . . . . . 5

3. ANALYSIS AITD EVALUATION OF RELEVANT FINDINGS • • • • • • • 6

3.1 Geostationary Orbit . . . . . . . . . . . 6

3.1.1 Physical Nature of Geostationary Orbit . . . 6

3.1.2 International Space Law . . . . . . . . . 8

3.1.2.1 International Customary Law . . . 9

3.1.2.2 The Outer Space Treaty of 1967 . 10

3.1.3 The 'Bogota Declaration' and Arguments Pro

and Con ................. . 14

3.1.3.1 The 'Bogota Declaration' . . . . 14

3.1.3.2 Arguments Pro and Con . . . . . 15

3.1 .4 Conclusion . . . . . . . . . . . . . . 19

3.1.5 ITU Instruments . . . . . . . . . . . . 20

3.1.5.1 Conclusions . . . . . . . . . 24

3.2 Microwave Frequency Allocation . . . . . . . . 27

3.2.1 ITU's Role ................. . . 27

3.2.1.1 Purposes of ITU . . . . . . . . 28

3.2.1.2 Meaning of 'Telecommunications' . . 29

3.2.1.3 Conclusion . . . . . . . . 32

3.3 Microwave Exposure Standard . . . . . . . . . 33

3.3.1 Nature of Microwave Beam . . . . . . . . 34

3.3.2 Effects of Exposure . . . . . . . . . . . 34

3.3.3 International Aspects........... . 35

3.3.4 Conclusion . . . . . . . . . . . . . 36

4. KEY ISSUES, OPTIONS, STRATEGIES AND TIME FRAMES • • • • 36

5. RECOMMENDATIONS FOR FURTHER STUDIES . . . . . . . . . . 51

5.1 Short-Term Studies . . . . . . . . . . . . 51

5.2 Long-Term Studies . . . . . . . . . . . . . 52

6. BIBLIOGRAPHY . . . . . . . . . . . . . . . . 64

7. APPENDIX ('Bogota Declaratión') . . . . . . . . . . . 77 


\section{INTRODUCTION}

\subsection{Background}

The exhaustible and dwindling supplies of conventional energy brought into sharp focus in recent years have directed attention at the national level toward the possible utilization of a virtually inexhaustible source of energy, namely, solar power. One of the current scientific concepts involves a Satellite Power System (SPS) in which satellites in geostationary orbit (GEOSAT-s) would collect light energy from the sun and convert it, first, to electricity and, then, to microwaves for transmission to earth and subsequent reconversion to electricity.

The technological feat of setting up such SPS is estimated to involve a very large investment running into billions of dollars. A careful analysis of all the factors and ramifications, including the impact of such project on socio-economic, legal, environmental, international and other considerations and an evaluation of alternative courses of action and their likely outcomes and effects is imperative before any rational decisions can be made.

\subsection{Objective and Tasks}

The objective assigned to this paper is to assess the problems in obtaining international agreements on geostationary orbit availability, microwave frequency allocations and microwave exposure standards. 
In accomplishing the above objective, the set tasks of this paper are threefold; first, to delineate in the light of historical precedents the problems that will need to be resolved, and the potential time delays in doing so to obtain agreements in these three basic areas; second, to identify and make a preliminary evaluation of alternative strategies, including perhaps, foreign or United Nations' participation in the SPS program to facilitate such agreements and third, to establish areas requiring additional study and provide a recommended approach.

\subsection{Assumptions}

The SPS concept, stipulated as an assumption or guideline

for this paper, has been described in the following terms:

The SPS concept involves placing a satellite equipped with large solar cell arrays in orbit around the earth. The arrays collect light energy from the sun and convert it to electricity, which is then converted to microwaves and beamed by a transmitting antenna located on the satellite to a receiving antenna located on the ground. The receiving antenna (rectenna) changes the microwaves back into electricity which can then be fed directly into the utility network. Both the satellite and the rectenna are on the order of 100 square kilometers in size and the system is designed so that each rectenna will provide 5,000 megawatts to the utility grid. The scope of the concept can perhaps be placed in perspective by considering that the generating capacity of 20-30 of these satellites would be equal to all the electrical power generated in the United States in 1975. Furthermore, projected energy demand at the turn of the century as well as basic economics indicate that an even greater number of satellites be programmed. Such a system may be confidently anticipated to have far-reaching impacts on society. 1 


\subsection{Methodology}

In an attempt to achieve the set objective and carry out the indicated tasks, this paper in accordance with the required format will include:

(a) A survey of relevant literature and related work;

(b) An analysis and evaluation of relevant finding;

(c) A determination of key issues and general observations on options, strategies and time frames,

(d) Recommendations for further study, and a

(e) Bibliography and an Appendix.

\section{SURVEY OF RELEVANT LITERATURE}

The literature pertaining to the subject matter may be characterized as vast in a very generalized sense (especially in terms of background materials pertaining to the first task) but in a more specialized sense (especially with reference to the second and third tasks), it appears practically nonexistent.

\subsection{General Background Materials}

An obviously not exhaustive identification of general background materials includes:

books, treatises, monographs (published and unpublished);

articles, comments, etc. in legal, scientific and other journals;

yearbooks, monthlies, weeklies and other magazines as well as newspaper articles;

laws, executive orders, judicial and administrative decisions, congressional materials, particularly comrnittee and subcommittee hearings, reports on activities, 
meetings, etc. of governmental agencies and other public and private (especially professional) organizations;

international treaties and agreements (bilateral and multilateral, regional or global), including charters, statutes, etc. of international organizations (governmental and nongovernmental), resolutions, records, minutes of meetings, etc. of their organs, bodies, committees, consultants, etc.;

correspondence, interviews, discussions with officials and experts.

The listed sources are relevant to the extent that they relate to the subject matter of the present inquiry.

At first sight, the above list may appear too broad but upon closer scrutiny relevant materials may be found in virtually any of the indicated sources. To take a random example, a perfunctory glance may suggest relevance of the major space treaties currently in force, particularly the outer space Treaty of 1967, but further reflection and research may reveal possible relevance of a host of bilateral agreements, especially between the United States and other nations. Similarly, a first reaction may suggest relevant activities and records of the United Nations Committee on the Peaceful Uses of Outer Space (UNCOPUOS), its Technical and Legal Subcommittees, and those of the International Telecommunication Union (ITU) and its International Frequency Registration Board (IFRB) but a deeper inquiry may reveal some relevance of the possible role, interest or impact of such international organizations as, for instance, the World Meteorological Organization (VMO), the World Health Organization (WHO), the United IJations 
Educational, Scientific and Cultural Organization (UNESCO) and, possibly, others. That activities and publications of private organizations, national and international, ought to be kept in mind may be intimated by reference to such random examples as the meetings and conferences of the American Institute of Aeronautics and Astronautics, the American Astronautical Society and the Colloquia of the International Institute of Space Law of the International Astronautical Federation.

\subsection{Specialized Materials}

As intimated beforehand, there appears to be a dearth of materials and information more specially related to the areas of investigation, particularly those associated with the second and third tasks. References with very few exceptions if any are mostly brief, extremely general, and largely indirect as may be seen from relevant textual annotations. This seems more true with respect to published information relative to the topics of obtaining international agreements on microwave frequency allocation for transmission of electrical power and microwave exposure standards. In view of this, the present inquiry in the indicated areas falls largely on virgin grounds based on a somewhat speculative assessment with whatever pitfalls and errors in subjective judgment that may entail. Additionally, -- apart from the subject matter's importance -the above fact accounts for what appears to be a rather lopsided emphasis on the treatment accorded to issues of geostationary orbit availability. 
An itemized, selective list of relevant general background and specialized materials may be found in the attached Bibliography

\section{ANALYSIS AND EVALUATION OF RELEVANT FINDINGS}

Our analysis and evaluation of relevant findings will start with a discussion of the issues involved in obtaining international agreements on geostationary orbit availability for power transmission by satellite and move on to such issues relative to microwave frequency allocations and microwave exposure standards.

\section{I Geostationary Orbit}

The technological advances of the space age have opened the door toward the increasing utilization of the so-called "geostationary orbit" by satellites for telecommunication, broadcast, meteorological and other services. 2 Wore recently, the possible utilization of geostationary orbit by satellites for purposes of solar energy transmission to earth has come under serious consideration. 3

\section{1 .1 Physical Nature of Geostationary Orbit}

The geostationary orbit is a circular orbit at a distance of approximately 22,300 miles $(35,800$ kilometers) above earth's equator. A satellite placed in this orbit turns about the polar axis of the earth in the same direction and with the same period as those of the earth and its orbit lies in the plane of the equator. Such satellite appears stationary in relation to 
the underlying point.

The space occupied by GEOSAT-s has been described as a "three dimensional corridor" in which satellites move at different altitudes, speeds and inclinations to the plane of the equator. ${ }^{4}$ While this corridor has its obvious limitations with respect to its physical size, the major concern has been the prevention of electromagnetic interference with other satellites and other users of the radio spectrum. The minimum separating distance required between GEOSAT-s may vary depending on the type of criteria used for arriving at a determination. These criteria include the size of the satellite, the stability of the orbit, the degree of tolerated electromagnetic interference, the state of technology, and other factors. This may explain the wide disparaties in the estimates of the maximum number of satellites (ranging from 180 to 1800 ) that could occupy the geostationary orbit at a given time. 5 As a recent U.N. study put it: "It is impossible to state how many satellites can be accomodated in the geostationary orbit. It is, however, possible to find out if a specific satellite system, with all physical parameters defined would interfere with other systems or not". 6 In 1977 there were 9 satellites placed in geostationary orbit ${ }^{7}$ and the total number in orbit reached about 100 in that year. 8

It has been estimated that between 1980 and 1991 there will be 274 geostationary satellites launched and that there will be 239 active satellites in geostationary orbit during 1990.9 Whatever the eventual increase will be--which is expected to 
continue with technological advancements and the possible emergence of additional types of uses--it appears that continued increase in the number of claims to the use of the geostationary orbit is likely to create overcrowding problems presenting harder choices with respect to the determination of priorities, the allocation of functions and uses, both domestically and internationally. ${ }^{10}$ The validity of this observation appears to be--in a very general sense-substantiated by the International Telecommunication Convention (ITC) of 1973 which--in dealing with the technical aspects of the use of frequency bands for space radio services describes the geostationary satellite orbit as one of the "limited natural resources". While the use of this particular phrase may have been somewhat unfortunate if compared to such conventional resources as copper or iron ore, it does convey the idea of the finite availability of geostationary orbital positions for orderly and beneficial uses.

In order to be able to make an appropriate assessment of the problems that may arise in obtaining international agreements on geostationary orbit availability, it appears essential to review the relevant lex lata of international space law, the recent claims of equatorial countries to segments of the geostationary orbit, the positions of other countries regarding these claims, and some of the ITU instruments which have a bearing on the subject.

\subsubsection{International Space Law}

Most of the applicable provisions of international space law which bear on our subject matter have been quite extensively analyzed in an earlier study. ${ }^{12}$ The general conclusion of that study was 
that "existing principles of space law present no fundamental impediments to the development and implementation of a satellite power system."13 Inasmuch as this writer is in basic agreement with that general conclusion and most of its supporting premises which were drawn from a detailed examination of relevant provisions, it would appear superfluous, if not redundant, to reanalyze--even if it were likely to be done in a somewhat different form and perhaps with different emphasis--the same stipulations in detail, the more so since the weight of authority including state practice to date appears to support it. However, a few additional observations concerning the permissibility of the utilization of the geostationary orbit by satellite solar power systems under current international law may be necessary to put the subject matter into proper perspective.

One of the very first issues in connection with the applicability of international space law to the geostationary orbit area is whether or not it is located in outer space. If it is not, the space treaties would not apply to it short of an explicit provision to the contrary.

\subsubsection{International Customary Law}

At the beginnings of the space age, there have been many theories and proposals advanced to determine the more precise demarcation line between air space and outer space not from a physical but from a legal point of view. ${ }^{14}$ Despite these efforts there has been no internationally accepted determination of where outer space precisely begins. 
While there has been no demarcation of the more precise boundary line between air space and outer space, many years of spacial experiments, both before and after the conclusion of the Outer space Treaty, 15 have seen the emergence of what has been described as a new rule of customary international law to the effect that artificial earth orbiting satellites move in outer space. ${ }^{16}$ This observation--made prior to the recent claims of sovereignty by equatorial countries over segments of the geostationary orbit above their territories 17 -was based on the fact that no formal objection had been made to the orbiting of such satellites by underlying states.

Since geostationary satellites orbit at heights far above many other earth orbiting satellites, there can be no doubt that the geostationary orbit area is in outer space. Until the recent claims of equatorial countries, the legal validity of the statement that earth orbiting satellites move in outer space appears not to have been challenged by any state.

\subsubsection{The Outer Space Treaty of 1962}

The Outer Space Treaty of 1967 was negotiated in pursuance of a desire to establish principles governing man's activities in outer space. These activities at the time of conclusion of the Outer space Treaty and beforehand related mostly to experiments conducted with artificial earth orbiting satellites. Therefore--short of any evidence to the contrary--the logical contention appears to be that the drafters intended the outer space Treaty to apply to such activities. ${ }^{18}$

One of the cardinal principles incorporated in the outer space Treaty of 1967 is the freedom of exploration and use of outer space 
by all states without discrimination of any kind, on a basis of equality and in accordance with international law. 19 In view of the fact that the geostationary orbit area is in outer space, the principle of freedom of exploration and use is applicable to it.

One limitation on the above provision is that the exploration and use must be carried out for the "benefit and in the interests" of all countries irrespective of their degree of economic or scientific development. 20 This so-called 'common interests' provision, however, has not been regarded as requiring states to share the benefits in any specific manner but rather as an expression of desire that the activities should be beneficial in a general sense. 21 Space activities pertaining to telecommunications, broadcast, meteorology and solar power transmission--generally speaking--may be regarded as beneficial to all countries. Thus an engagement in any such activity would appear to satisfy the requirement of the 'common interests' clause.

What has been frequently overlooked, however, possibly because of its self-evident nature is that the "benefit and interests" of the country conducting the exploration and use must also be taken into account, otherwise the exploration and use would not benefit "all" countries. The general scope and applicability of the 'common interests' provision has been analyzed in detail by this writer in 1971 and for purposes of brevity only the following few remarks will be quoted:

[T] he exploration and use must be in the "interests" of ail countries. The plural term "interests" seems to indicate that more may be involved than just the vague, general "interest" of all countries. In a sense the plural phrase may perhaps be regarded as a victory for 
the less developed countries which entertained strong hopes of receiving benefits from man's exploration and use of outer space.

What is or is not to the benefit and in the interests of all countries may not always lend itself to an easy determination. Something which is thought to be of benefit to a country on the basis of available information and criteria today may be regarded on the basis of new information and criteria detrimental tomorrow. Also, who is going to determine whether or not a particular exploration and use is in a given case for the benefit of all nations? Since there is no provision in the Treaty for the settlement of disputes, it is likely that each state -- short of an amicable disposition of the issue -- would insist on its own interpretation...

Whether or not only the "exploration and use" must be beneficial to all countries or also the "results", that is, the benefits derived from such exploration and use, is a further very important question...

Assuming then for a moment that the "results" of exploration and use were meant, the question arises whether or not "all" such results or benefits were intended and, if so, must all such results be "shared" in order to constitute a benefit to all countries?...

...Thus it would appear that appropriate international agreements would have to be concluded before equal enjoyment of benefits could be regarded as more than a broad statement of general policy. 22

The foregoing observations support the proposition that the so-called

'common interests' clause incorporated in Art. I (1) of the Outer Space Treaty is not self-executing but rather a kind of imperfect legislation in that it expresses an aspiration couched in very general terms which could not be specifically implemented without further elaborations and guidelines particularly those relating to the determination of the degree and nature of the sharing and the kinds of benefits that are to accrue. However, the development of internationally acceptable guidelines governing the use of geostationary orbit would create a more favorable environment for the SPS. 
Insofar as the ban on national appropriation incorporated in Article II of the Outer Space Treaty is concerned, it would appear that the placing of a satellite in geostationary orbit would not constitute national appropriation. From the beginnings of the space age the principle 'first come, first served' was followed and the Outer space Treaty did not place a limitation on this with respect to free space, and state practice to date appears to have confirmed it. As correctly observed by Professor Aldo Armando Cocca, Argentina's representative before the U.N. Committee on the Peaceful Uses of Outer Space (UNCOPUOS): "though everybody has a right to piace a space object in orbit, the second in time is to respect the route chosen by the first." ${ }^{24}$ He called this rule similar to the principle of "droit de route" in Argentine law. 25

While the keeping of a GEOSAT in orbit for a period of 30 years may be argued to constitute national appropriation--since 30 years may satisfy the requirement that to constitute appropriation the act must be done with a "sense of permanence"26-- in actuality it would not if geostationary orbit is regarded as a natural resource as characterized by the 1973 International Telecommunications Convention and asserted by the equatorial countries. 27 The reason is that there is authority to support the view that the ban does not relate to natural resources. 28 This position also appears to have been shared by the Legal Subcommittee of UNCOPUOS, at least insofar as natural resources of the moon and other celestial bodies were concerned. 29 


\subsubsection{The 'Bogota Declaration' and Arguments Pro and Con}

It was in October 1975 during the 30 th session of the U.N. General Assembly that Colombia first claimed a segment of the geostationary orbit above its national territory. ${ }^{30}$ The claim was predicated on the argument that the geostationary orbit was not included in the conception of outer space alluded to in the outer Space Treaty of 1967. This position was reiterated by Colombia during the next session of the General Assembly in 1976 and similar positions were taken by Ecuador and Panama. ${ }^{31}$

In November 1976, eight equatorial countries (Brazil, ${ }^{32}$ Colombia, Congo, Ecuador, Indonesia, Kenya, Uganda and Zaire) met in Bogota to hammer out a unified position in relation to the geostationary orbit. Their conference ended on December 3, 1976, with what is known as the 'Bogota Declaration. 33 in which they set forth their basic position on the legal status of the geostationary orbit.

In order to understand fully the position of the equatorial countries with respect to the geostationary orbit, it seems appropriate to review briefly the basic arguments set forth in the Declaration as well as subsequent statements both pro and con.

\subsubsection{The 'Bogota Declaration'}

The basic claim of the Bogota Declaration reduced to its bare essentials is that segments of the geostationary orbit (a natural resource) which lie above their territories are an "integral part" of the territory over which the equatorial countries exercise complete and exclusive sovereignty. ${ }^{34}$ This claim is accompanied 
by the statement that the devices to be placed permanently on the segment of a geostationary, orbit of an equatorial state require "previous and express authorization on the part of the concerned state" 35 and an additional assertion that the equatorial states do not condone existing satellites or the position they occupy on their segments of the geostationary orbit nor does the existence of said satellites confer any rights of placement of satellites or use of the segment unless expressly authorized by the state exercising sovereignty over the segment. ${ }^{36}$

The only clarification that the Declaration makes with respect to foregoing demand is that the equatorial states do not object to the free orbital transit of satellites approved and authorized by the International Telecommunication Convention when these satellites pass through their space territory in their gravitational flight outside their geostationary orbit ${ }^{37}$ and that the segments of the orbit corresponding to the open sea beyond national jurisdiction constitute the 'common heritage of mankind'. 38

\subsubsection{Arguments Pro and Con}

A sampling of some of the arguments advanced in the Declaration reveals that they have been based on such considerations as:

The geostationary orbit is a physical fact arising from the nature of our planet because it depends exclusively on its relation to gravitational phenomena caused by the Earth; 39

Under the current rules of the International Telecommunication Union, geostationary orbit was a limited natural resource over which the equatorial countries exercised permanent sovereignty in line with U.N. resolutions; 40

There is no satisfactory definition of outer space to support the argument that the geostationary orbit is included in outer space; 41 
The ban on national appropriation is not applicable in view of the lack of definition of outer space; 42

Technological partition of the orbit is inappropriate; ${ }^{43}$ The geostationary orbit is not covered by the outer space
Treaty;

The Outer Space Treaty can not be a "final answer"; 45

To the preceding considerations certain additional points

were added in the course of subsequent U.N. discussions in 1977

and 1978. Some of them were expressed in such statements as:

The prevailing uncertainty on the matter of outer space was illustrated by the variety of criteria suggested for its definition; $46^{1}$

Until an international definition of outer space had been arrived at the provisions of domestic law would apply to demarcate space;

There is no right of succession in regard to satellites; ${ }^{48}$

Exercise of sovereign rights is in keeping with positive international law; 49

Countries that had not ratified the treaty were not bound by it;

Orbit was unique because it was the only point at which it was economically feasible to maintain a satellite in a stationary position and because it was the only feasible position for solar energy platforms; 51

Geostationary orbit was a limited natural resource because of its possible saturation with solar energy platforms and telecommunication frequencies. 52

That the legal and scientific considerations which were invoked in support of the claim of equatorial countries had no valid basis became apparent from their overwhelming rejection by other countries represented before UNCOPUOS including, for instance, Australia, ${ }^{53}$ Belgium, 54 Czechoslovakia, 55 France, 56 
the German Democratic Republic, ${ }^{57}$ Iran, ${ }^{58}$ Italy, ${ }^{59}$ Mexico, ${ }^{60}$ Soviet Union, 61 United Kingdom, ${ }^{62}$ and the United States. 63

Some of the counter arguments were reflected in such statements as:

The concept of natural resources had never been defined in General Assembly resolutions; 64

Art. 33 of the International Telecommunication Convention had described the parameters of geostationary orbit from a purely technical standpoint and had never defined it in legal terms; the only stipulation of a legal nature in those regulations was that allocation of an orbital position could not confer permanent priority or possession; 65

Geostationary satellites were not permanently located at the same point on the equatorial plane; 66

No state ever protested against the ever-growing outer space activities carried out for the progress of civilization and the benefit of mankind; 67

The use of geostationary orbit was subject to the legal regime of the Outer Space Treaty; 68

There was no parallel between the jurisdiction of the coastal states extending over the continental shelf and the extension of national sovereignty to positions on the geostationary orbit; 69

A claim of sovereignty was valid only if it was based on effective occupation; 70

There was no legal or scientific basis for claiming national jurisdiction over segments of the geostationary orbit. The interest of mankind could be served only by free and equitable use, and exploitation of outer space by all countries claiming national sovereignty over the geostationary orbit did not serve these interests. All countries would lose if a monopoly over the geostationary orbit was established; 71

The geostationary orbit was a construction of the mathematical and scientific mind and belonged to all mankind; ${ }^{2}$

The view that geostationary orbit was a natural resource and subject to the sovereignty of the equatorial states was absurd requiring no further comment. 73 
While the strictly legal and technical arguments of the equatorial countries did not appear convincing, it is instructive to look at their underlying motivations which prompted the equatorial countries to put forth their claims. Such motivations reflected economic aspirations couched in terms of fundamental justice, equity and fairness as revealed by a brief sampling of the following statements:

ITU solutions are impracticable and unfair and would considerably increase the exploitation costs of the geostationary orbit especially for developing countries which do not have equal technological and financial resources as compared to industrialized countries who enjoy an apparent monopoly in the exploitation and use of geostationary orbit;

Both the geostationary orbit and the frequencies have been used in a way that does not allow equitable access of the developing countries that do not have the technical and financial means that the great powers have; 75

The ultimate justification for the Declaration is directed "towards rendering tangible benefits to their respective people and for the universal community"; 76

The application of the 1967 Treaty did not reflect the spirit of its drafters; 77

Outer space had been beneficial only to a few countries instead of to all countries; 78

A more just international order could not be achieved if the use of outer space was left only to a few countries; 79

The issue of the geostationary orbit should be resolved in accordance with the aims of the New International Economic Order; 80

The geostationary orbit must be used in priority for the benefit of the developing countries in order to help to narrow the gap between the developing countries and the industrialized countries on an equitable basis; 81 
In order to attain their economic aspirations on the basis of justice, equity and fairness the equatorial countries wanted to renegotiate the Outer Space Treaty, more specifically,

First, to negotiate a definition or delineation of outer space which would take into account the interests of the equatorial countries;

Second, to negotiate a legal regime to govern the use of the geostationary orbit taking into account the genuine interest of the international community and the concerns of the equatorial countries; 83

Third, to negotiate regional and subregional agreements with other Latin Amerjican states for the joint use of the geostationary orbit; 84

Finally, to create a new Outer Space Authority under the auspices of the United Nations. 85

The reaction to what appears to have motivated the claim of equatorial countries found expression in a number of statements, including that of Brazil, an observer at Bogota. Among them are:

Understood the anxiety about the use of geostationary orbit and supported the proposal to study the scientific and technical aspects in order to elaborate an international legal regime on geostationary orbit (Australia); 86

Concerns of the equatorial countries were not absurd, particularly since they were countries seeking to achieve development. They are worthy of note and should be examined carefully in the context of the 1967 Treaty (Belgium); 87

Was in favor of the formulation of a specific legal regime taking into account the unique nature and risks of saturation of the geostationary orbit safeguarding the legitimate interests of all states particularly those over whose territories the orbit passed (Brazil) $;^{88}$ 
It might be necessary to regulate the orbit within the framework of the Outer Space ireaty (France), 89

The interests of other states must be taken into account in a spirit of good faith and cooperation 90 (Germ. Dem. Rep.);

Not opposed to the discussion of the issue of geostationary orbit (Iran); 91

It was necessary to develop a legal regime in which "the special interests of the equatorial states" would be taken into account (Mexico); 92

All countries should have equitable access to the geostationary orbit (Nigeria); 93

Prepared to recommend, for consideration of the General Assembly, a draft resolution concerning the legal aspects of geostationary orbit, if no consensus of these questions could be reached in the Legal Subcommittee (Soviet Union) $; 94$

The best solution was to have all states equitably share the benefits of the geostationary orbit (U.K.); 95

\section{1 .4 Conclusion}

From the preceding review of outer space related instruments and deliberations it appears that the claims of the equatorial countries to segments of the geostationary orbit are legally and scientifically untenable. At the same time, it also appears that in the Legal subcommittee of UNCOPUOS there has been a fairly substantial support for equity and fairness which would favor or at least leave the door open for consideration, within the framework of the Outer space Treaty, of the development of legal principles to govern the use of geostationary orbit. The development of such principles is likely 
to become a major issue before unCoPuos but the United States appears to have overwhelming support for the view that no part of the geostationary orbit is subject to claims of sovereignty and that principles governing the use of geostationary orbit must be worked out within the framework of the Outer Space Treaty.

\section{1 .5 ITU Instruments}

The beginnings of the space age did not develop according to an a priori plan but as a result of an evolutionary process. Countries which placed satellites in orbit and beyond did not ask for any permission and there were no series of official protests. The vastness of outer space appeared to offer unlimited opportunities of exploration and use for any country that wished and could undertake them. There was only one limitation -- largely by reason of common sense -- the 'first come, first served' rule which became a firmly embedded concomitant of the principle of freedom of exploration and use of outer space. ${ }^{96}$ Under this rule the late comer would not be entitled to priority with respect to activities of an earlier user.

A glance at the history of the International Telecommunication Union reveals that its patterns of practices were based on the recognition of the same rule. However, the limited nature of availability of the electromagnetic spectrum and the geostationary orbit for beneficial use coupled with increasing opportunities and demands for their uses has led to efforts by developing nations to alter the 'first come, first served' rule which in their view favored the technologically advanced countries. The results of their efforts were reflected in a series of resolutions, articles and regulations 
adopted by ITU bodies. A brief review of some of the relevant instruments is essential in order to identify problems that are likely to be encountered in negotiating international agreements on geostationary orbit availability.

It was during the 1971 World Administrative Radio Conference for space Telecommunications (WARC-ST) that a resolution was adopted which took into account that all countries had "equal rights in the use of both the radio frequencies allocated to various space radiocommunication services and the geostationary satellite orbit for these services" and that "the radio frequency spectrum and the geostationary satellite orbit" were "limited natural resources" which were to be "most effectively and economically used." 97 In recognition of this, the legally not binding instrument went on to resolve:

1. [T]hat the registration with the ITU of frequency assignments for space radiocommunication services and their use should not provide any permanent priority for any individual country or groups of countries and should not create an obstacle to the establishment of space systems by other countries;

2. [T]hat, accordingly, a country or a group of countries having registered with the ITU frequencies for their space radiocommunication services should take all practicable measures to realize the possibility of the use of new space systems by other countries or groups of countries so desiring. 98

In another resolution the same conference reiterated the importance of making the best use of the geostationary orbit and the frequencies assigned to the broadcasting satellite service.99 Also, the same conference revised the Radio Regulations which have the force of a treaty to provide, in part, for a procedure to coordinate use of the geostationary orbit in the following manner: 
An administration (or one acting on behalf of a group of named administrations) which intends to establish a satellite system shall, prior to the coordination procedure .... send to the International Frequency Registration Board not earlier than five years before the date of bringing into service each satellite network of the planned system, the information listed....

Before an administration notifies to the Board or brings into use any frequency assignment to a space station on a geostationary satellite or to an earth station that is to communicate with a space station on a geostationary satellite, it shall effect coordination of the assignment with any other administration whose assignment in the same band for a space station on a geostationary satellite or for an earth station that communicates with a space station on a geostationary satellite is recorded in the Master Register, or has been coordinated or is being coordinated under the provisions of this paragraph. For this purpose, the administration requesting coordination shall send to any other such administration the information listed....100

The WARC-ST resolutions were followed by binding provisions in

the 1973 International Telecommunication Convention (ITC) stipulating rational use of the radio spectrum and geostationary orbit (spectrum/orbit) and the avoidance of harmful interference. The provisions state in part that:

In using frequency bands for space radio services Members shall bear in mind that radio frequencies and the geostationary satellite are limited natural resources so that countries or groups of countries may have equitable access to both in conformity with the provisions of Radio Regulations according to their needs and the technical facilities at their disposal. $10 \mathrm{l}$

All stations, whatever their purpose, must be established and operated in such manner as not to cause harmful interference of other Members, or of recognized private operating agencies, or other duly authorized operating agencies which carry on radio services, and which operate in accordance with the provisions of the Radio Regulations.102

Another ITC provision specifically extended the responsibilities of the International Frequency Registration Board (IFRB), an ITU organ, in order to effect "an orderly recording of the positions 
assigned by countries to geostationary satellites", "to furnish advice to Members... with a view to the equitable, effective and economical use of the geostationary satellite orbit" and "to perform any additional duties" relating to "the utilization of the geostationary satellite orbit". 103

The importance of efficient use of the spectrum/orbit and the principle of equal rights of all countries found further expression in the Preamble of the Final Acts of the 1977 World Administrative Radio Conference for the Planning of the Broadcasting-Satellite Service in Frequency Bands $11.7-12.2 \mathrm{GHz}$ (in Regions 2 and 3 ) and 11.7-12.5 GHz (in Region 1) (WARC-BS). In it, the signatories, inter alia, stated that they bear in mind:

[T] he importance of making the best possible use of the radio-frequency spectrum and the geostationary-satellite orbit as well as the need for an orderly development of the services to which these bands are allocated;

and take into account:

[T] he equal rights of all countries, large and small, even those countries which are not represented at the Conference.

The 1977 WARC-BS adopted a plan (to go into effect on January 1, 1979) designating frequency assignments in the aforementioned bands and positions in the geostationary orbit for regions 1 (Europe, Africa, the USSR and Mongolia) and 3 (Asia and the Pacific). 104

Postponement of the immediate adoption of an orbital position and Erequency channel plan for Region 2 (the Americas) 105 was in a sense a victory for the evolutionary approach advocated by the United States permitting future technological advances to be taken into account. To achieve this the acceptance of two compromises was necessary: An 
arc segmentation approach under which alternating segments of the geostationary arc were allocated on a primary basis to the broadcasting-satellite service and the fixed-satellite service; and the holding, not later than in 1982, of a Regional Administrative Radio Conference to draw up a detailed plan for the broadcastingsatellite and fixed services in Region 2. 106

The equatorial countries -- with the exception of Indonesia-made reservations to the effect that they do not accept and are not bound by the resolutions, agreements and decisions of the conference regarding the location of geostationary satellites on the segment of the orbit over which they exercise sovereign rights and that the positioning of such satellites will require their prior authorization. 107 Indonesia made a separate reservation in which it invoked in part the Bogota Declaration. 108

The United States joined with a number of countries rejecting the claims of the equatorial countries and declaring that the decisions of the conference to assign frequencies and orbital positions in the geostationary orbit were fully in accordance with the 1973 ITC by which the conference was bound. 109

\subsubsection{Conclusions}

The preceding review of ITU instruments and related discussions appears to indicate that the 'first come, first served' principle with respect to the use of the geostationary orbit has basically remained unaltered from a strictly legal point of view. While states, in general, abide by ITU resolutions, they are not legally bound by them. However, to the extent that such resolutions express 
a substantial consensus by a large number of states, they should be considered as relevant factors in revealing trends and indicating problems that may be encountered with respect to reaching international agreements on geostationary orbit availability. Additionally, provisions incorporated in instruments having the force of a treaty speak clearly of efficient and economic use and equitable access of countries and groups of countries to the geostationary orlit. This, in turn, implies that there is no legal right to the permanent utilization of a particular orbital position, even less to a claim of sovereignty or ownership.

The views reflected in a number of international instruments appear to bring forcefully to the fore the key issue that policy makers will increasingly have to face as science and technology provides more practical uses of the orbit. This is how to translate--what the ITU calls--the "efficient and economic use" and "equitable access" into more specific legal and technical principles and rules relating to the geostationary orbit for--what the outer Space Treaty calls--the "benefit and interests" of all countries. The legal aspects of this issue are likely to be faced by U.S. representatives next year before uncopuos and its Legal subcommittee whereas its technical aspects will come before its scientific subcomittee and the 1979 WARC, the agenda of which includes a review and, if necessary, revision of the Radio Regulations, including procedures for coordinating the use of geostationary orbit. Some of the relevant policy options and strategies will be discussed in section 4 . 


\subsection{Microwave Frequency Allocation}

Satellites in geostationary orbit would use microwave beams for transmission of solar energy to earth.

The nature of microwave transmission does not differ basically from other transmission except for density, but the purpose does differ, in one case being telecommunications, in the other, large-scale power transmission. While several frequencies have been considered in connection with the SPS -- because of what appears to be its advantages over other frequencies -- 2.45 $\mathrm{GHz}$ has been proposed for possible use. 110

In order to determine the problems which may be encountered in reaching international agreements on microwave power frequency allocation, it appears essential to examine the existing international institutional framework with particular reference to frequency regulation within the radio spectrum.

\section{2 .1 ITU's Role}

Because of Iimitations on the availability of the radio spectrum for beneficial uses, an international organization, the International Telecommunication Union (ITU), has been entrusted with the responsibility of working out rules and procedures with a view toward maximizing the spectrum's efficient utilization and preventing any harmful interference.

ITU's recent involvement during the 1977 WARC-BS in the preparation of a plan for allocating geostationary orbital slots and frequencies for broadcast-satellite services has brought to 
the fore the key issue which may have to be faced in international negotiations regarding orbit availability for GEOSAT-s.

Insofar as frequency for microwave power transmission is concerned, the most crucial issue pertaining to ITU is whether it would have competence to deal with such transmission. To determine this, it is necessary to scrutinize the International Telecommunication Convention (ITC) which defines the purposes of ITU.

\section{2 .1 .1 Purposes of ITU}

The current basic instrument of ITU was signed at MalagaTorremolinos in 1973 and entered into force on January 1, 1975. 111 Under its provisions the purposes of the Union are:

(a) to maintain and extend international cooperation for the improvement and rational use of telecommunications of all kinds;

(b) to promote the development of technical facilities and their most efficient operation with a view to improving the efficiency of telecommunications services, increasing their usefulness and making them, so far as possible, gonorally available to the public;

(c) to harmonize the actions of nations in the attainment of those ends. 112 (Emphasis added).

If one scrutinizes the avowed purposes of ITU, it appears

that the maintenance and extension of international cooperation by ITU must relate to the improvement and rational use of "telecommunications of all kinds" and to the "improvement of the efficiency of telecommunications services". Thus under subparagraphs (a) and (b) "telecommunications" is the keyword and subparagraph 
(c) refers back to "those ends" mentioned beforehand under subparagraphs (a) and (b).

Insofar as the various activities of ITU are concerned, they are to take place in furtherance of the purposes mentioned above which involve "telecommunications." Also, the name of the organization "International Telecommunication Union" clearly suggests that the organization is to deal with "telecommunication".

\subsubsection{Meaning of 'Telecommunication'}

In order to determine whether ITU has authority to deal with microwave frequencies for purposes of large-scale power transmission, it appears that the word "telecommunication" must be defined.

Telecommunication is defined in the Annex to the ITC to mean "any transmission, emission or reception of signs, signals, writing, images, and sounds of intelligence of any nature by wire, radio, optical or other electromagnetic systems." This definition is not limited to terrestrial services but also extends to space communications. 113

One of the first issues pertaining to the above definition is whether a transmission in and by itself by wire, radio, optical or other electro-magnetic systems could be regarded as "telecommunication." However, a close reading of the sentence leaves little doubt that all three words, namely, "transmission, emission or reception" refer to "signs, signals, writing, images and sounds of intelligence of any nature" and not just to any "transmission, emission or reception" without any reference to "signs, signals, 
writing, images and sounds of intelligence of any nature." In view of this, it appears that the ITU has competence to deal with the indicated type of transmissions including microwave lelectromagnetic) transmissions which involve "signs, signals, writing, images and sounds of intelligence."

The next issue is whether the use of microwaves for power transmission involves transmission of "signs, signals, writing, images and sounds of intelligence." If it does not then ITU has no competence to leal with frequencies for such microwaves.

Power transmission by microwaves does not appear to involve anything that is normally identified by the words "sign, writing, image and sounds of intelligence". Therefore, the question is whether it could be regarded as a 'signal'. There are two possible answers to this question depending on the interpretation of the word 'signal'.

The relevant dictionary definition of the word 'signal' is an "impulse or sound wave transmitted or received". 114 Microwave under this definition may be interpreted to fall under the category of an impulse, irrespective of the purpose for which the microwave is being used. Another definition of 'signal' relating specifically to communications is "an event that serves, or at least is capable, to start some action." 115 Also under this definition microwaves for power transmission would appear to be signals. However if the word 'signal' is interpreted as a means of communication or telecommunication in the more conventional sense of the term, it becomes apparent that communication or telecommunication would have to be defined even though such procedure may 
appear circuitous. A modern definition of the word 'telecommunication' confines the term to "the sending and receiving of messages over a distance by electrical means".116 Under such interpretation microwaves utilized for power transmission would not be 'signals' in the sense of 'messages' and, consequently, the ITU would appear to have no competence over them.

Despite the force of the preceding logic--should it be correct--it might be pointed out that one of the functions of ITU is to coordinate uses of the radio frequency spectrum "in order to avoid harmful interference between radio stations of different countries" and to coordinate efforts "to eliminate harmful interference between radio stations of different countries." 117 While such interference has to arise between radio stations of different countries, it may be argued that any activity even if not related to telecommunications which would interfere with the ITU's discharge of its assigned functions could be regarded to be of legitimate concern to ITU. Thus, while ITU may have no competence to deal with microwave frequencies for purposes of power transmission if such transmission is not regarded as telecommunication, any harmful interference even though arising out of a source other than communications would fall under ITU's competence.

An additional consideration in the foregoing line of reasoning is that the SPS would also have to use frequencies for normal telecommunications between ground controllers and the satellite whether manned or unmanned. This would clearly fall into ITU's 
competence and as a result it would appear that--in order to discharge its functions--ITU would have to take into account the geostationary position of the satellite and its assigned frequencies both for power transmission and telecommunications.

A more far-fetched thought would be to argue that much of the energy transmitted via the microwave beams would most likely be used also for conventional communications purposes and, therefore, it should be at least to that extent under the jurisdiction of the ITU. While this argument may have some potential attraction, it appears to disregard the basic premise, namely, that the ITU's competence relates to activities involving telecommunication and not to any prior phase of power generation even if such power is subsequently used for telecommunication.

\section{2 .1 .3 Conclusion}

The conclusion that emerges with respect to the issue of microwave frequency allocation for the SPS is that strong arguments appear to support the proposition that ITU has competence to deal with such frequencies and, by necessity, it would also have to determine geostationary orbital positions if it is to fulfill its assigned functions in a proper manner. The interpretation of the definition of the word 'telecommunication' in a broader than the conventional sense is in no way in conflict with what has been described as the general tendency of the ITU to resolve newly emerging problems of the space age within its existing structures. ${ }^{118}$ 
If the result of the aforementioned broad interpretation is acceptable to the ITU, and there is little reason to believe that it would not, it would be within the competence of ITU to follow its IFRB procedures relative to the registration of frequency assignments in case of microwave power transmission in the same manner as it has in relation to other frequencies of the radio spectrum. 119 However, before any such procedures can be prudently put into effect, it will be necessary for the ITU to determine through appropriate studies and relevant findings any radio frequency (RF) interference, including the detailed and specific effects on radio astronomy, ship-borne radar, communications systems and other services. It may be noted that some preliminary studies have already been undertaken by the International Radio Consultative Committee (CCIR), an ITU organ, in connection with preparations for the 1979 WARC. 120 Such studies will have to be periodically updated to keep abreast of scientific and technological developments which may result in reduction or possibly even in complete elimination of RF interference as may perhaps be the case if laser beams were used for power transmission.

\section{3 Microwave Exposure Standards}

One of the major concerns involving the transmission of microwave beams from geostationary satellites to selected places on earth relates to the all-important question of what effect exposure to such transmission is going to have on humans and biota 
in the receiving area, on the ground and in the air space which the beams traverse.

\subsubsection{IJature of Microwave Beam}

Scientists tell us that a fairly precise pointing of the microwave beam can be achieved with negligible risks in case of aberration. 121 The microwave power flux density would be the greatest in the center and would decrease toward the edges of the roughly 10 square kilometers diameter beam corridor. ${ }^{122}$ It is estimated that beyond $10 \mathrm{kilometers}$ from the beam center the microwave power density would meet the lowest foreign levels set for continued exposure to microwaves. 123 Mesh shielding for workers could be employed within a $10 \mathrm{mile}$ radius about the beam. 124

\subsubsection{Effects of Exposure}

The danger of microwave exposure with reference to the proposed power density of the microwave beam has been described by one authority in the following terms:

"Short exposure would not harm anyone, if he were to walk into the beam... However, one would not want to live there. At the edges of the receiving antenna site the power densities associated with the microwave beam will be well below U.S. permissible level, for continuous exposure to microwave, which is 10 miliwatts per square centimeters, and more than likely they will also mejt the Russian levels which are 1,000 times less."

Effects of exposure on humans and biota must be determined and found nationally and internationally acceptable under all kinds of potential situations, including effect on workers at the site 
of the receiving antenna, effects on sick people, affects under accident or other abnormal situations at the center of the beam and elsewhere both under short and long term exposure. Even though it has been pointed out that the projected effects on birds and on aircraft flying through the beam are negligible, a more precise determination should be made by actual experiments. 126 .

\subsubsection{International Aspects}

In view of the obligations imposed by international law especially the Outer Space Treaty requiring avoidance of "adverse changes in the environment of the earth" and appropriate international consultations in case of potentially harmful interference-which have been reviewed in an earlier study ${ }^{127}$--it would seem that both the literal interpretation of the law as well as prudence on the part of the United States would require that it enter into consultations with cther governments regarding the development and formulation of acceptable international standards of microwave exposure.

The importance of such move cannot be overemphasized in view of the fact that a review of past practices appears to indicate wide divergence of views with respect to the determination of standards by different countries. As pointed out previously, the U.S. standard, which relates primarily to industrial or occupational type exposure, is 10 miliwatts per square centimeter whereas the more stringent U.S.S.R. standard is set at the level of 10 
microwatts per square centimeter. Other countries use intermediate standards. 128

\section{3 .4 Conclusion}

Acceptance of more stringent standards may impose additional scientific, technical and other tasks on SPS development programs. However, with respect to the biological effects of microwave exposure and possibly other effects on the environment, it appears that there can be no choice but to pursue the route leading toward general international acceptance in order to clear the United States of any possible charge of negligence, should some injury or damage arise because of the inadequacy of an internationally not accepted standard. Such general consensus could best be achieved by an appropriate international meeting with the possible assistance of the Scientific and Technical subcommittee of UNJCOPUOS or the World Health Organization (WHO). However, in all these situations it is likely that agreements may be reached much faster if the United States already has a cooperative agreement on the SPS with the country concerned. In this manner the framework provided by the cooperative bilateral agreement may be used to prepare the way for arriving at a general international consensus.

\section{KEY ISSUES, OPTIONS, STRATEGIES AND TIME FRAIIES}

The preceding analysis and evaluation of relevant findings in the three areas of investigation have brought several key issues to the fore. Their clarification will be essential for the determi- 
nation of policy options and relevant strategies and the projection of time needed to obtain agreements on geostationary orbit availability, microwave frequency allocation and microwave exposure standards.

\subsection{Definitions and Interpretations}

One of the very first major issues in negotiating international agreements with respect to geostationary orbit availability, microwave frequency allocations and microwave exposure standards will be a definition of power transmission by microwaves from space, bearing in mind both the legal and scientific implications. In a recent draft report the International Radio Consultative Committee (CCIR) defined the scientific parameters of 'free-space energy transmission by microwaves" as "the point-to-point transfer of energy through free-space by a highly collimated microwave beam".129 The report added that this technique constitutes "a unique technology" which "differs from the use of microwaves in free-space for point-to-point communication purposes because of its very high efficiency and the magnitude of the power" and also differs from "the traditional methods of receiving and processing radio energy in communications and location services."130

Closely associated with the issue of definition of microwave power transmission is that of 'telecommunication', particularly of the word 'signals' as it is used in the definition of telecommunication in the 1973 ITC. The definitions and their interpretations are key issues because the position taken in relation to them may determine whether or not the ITU has competence to deal with microwave energy transmission from space. This, in turn, may have farreaching effects on U.S. policy options and strategies in 
negotiating international agreements on orbit and frequency availability.

One of the vexing issues with respect to ITU's role as revealed in the course of the 1977 WARC has been how to reconcile ITU's lack of competence over geostationary orbital position assignments with its mandate to coordinate the efficient and economic use of the radio spectrum. This issue arose from the fact that geostationary orbital position and frequency spectrum can not be separated from one another for the purpose of coordinating or regulating any space services. 131 Thus the 1977 WARC approved a plan designating geostationary orbital positions and frequencies in specific bands for broadcasting-satellite services. While the plan reflects an $\underline{a}$ priori, rather than an evolutionary, approach with respects to Regions 1 and 3, it is clearly geared to "services". Additionally, its significance lies in the fact that it establishes ITU competence to deal with geostationary orbital positions in the indicated context in view of orbit/spectrum inseparability.

In the face of several key issues, one of the policy options for the United States would be to prepare a draft technical plan of ITU procedures relative to microwave energy transmission by GEOSAT-s and get an informal reaction from ITU and other appropriate sources, possibly in course of the next WARC meeting in 1979 . Such plan may be in the form of an evolutionary step-by-step outline indicating in sequence the problems that will have to be studied and the likely ITU groups and other forums before which they could be taken up.

If informal reaction to the draft plan is favorable, a more formal consideration may be sought, perhaps from a study group, possibly Study Group 2 or 4 of CCIR which have been concerned with 
harmful interference and the efficient utilization of geostationary orbit, respectively. ${ }^{132}$ A recommendation from such group, if it finds the SPS to fall within ITU's competence, would pave the way for the concretization of ITU procedures and would help negotiations with respect to microwave frequency and orbital allocations.

In case of unfavorable reaction the United States should be prepared to respond to the argument that ITU has no competence to deal with microwave frequencies and geostationary orbital positions for purposes of power transmission. As already indicated such argument is not entirely without foundation. However, support for its rejection may be found not only in the interpretation of the word "signals" in the definition of meaning of telecommunications and in the fact that all satellites, including power satellites, in the geostationary orbit must rely on radio communications in order to perform their functions, but also in the fact that coordination of use of all other frequencies not involving energy transmission by microwaves would still be within ITU's competence. Thus ITU procedures would still have to be followed to avoid harmful interference with other users of the radio spectrum.

Should there be strong opposition to the idea that ITU has competence to deal with transmission of power by microwaves, one option would be to make necessary amendments to the ITC, the Radio Regulations and IFRB procedures. Those opposed could argue that such changes would have far reaching effects on ITU which would no 
longer deal exclusively with telecommunications but also with microwave energy transmission, possibly limited to the earth-space arena. However, since the United States appears to wield substantial influence on the workings of ITU-related bodies, it may not be in its interest to accept a suggestion that another organization should be established to deal with energy transmission by microwaves.

\subsection{Claims of Equatorial Countries}

Another key issue for U.S. policy will be how to deal with the claims of sovereignty by equatorial countries over segments of their geostationary orbit and the additional assertion that segments of the orbit corresponding to the open sea beyond national jurisdiction are the "common heritage of mankind." This is a key issue because--according to scientific projections--power GEOSAT-s would likely occupy positions on the equatorial plane ${ }^{132}$ which would be, in part, over equatorial countries and, in part, over the Atlantic and Pacific Oceans.

Any circumspect U.S. policy regarding the claims of equatorial countries must take note of the discussions at the 17 th Session of the Legal Subcommittee of UNCOPUOS which clearly reveal the overwhelming conviction of its members that the legal and scientific arguments marshalled in support of the claim of equatorial countries were untenable.

At the same time, the discussions also disclose that a number of delegates appeared to take a somewhat conciliatory position with respect to a possible consideration by the subcommittee of the development of principles governing the use of geostationary orbit. 
This position, however, in no way implied that a new or different regime should be developed outside of the framework of the 1967 Outer Space Treaty. On the contrary, several delegates pointed out that the subcommittee had competence to discuss the elaboration of principles only if they were based on the Outer Space Treaty.

In view of the foregoing considerations and also in light of the 'common interests' clause in the Outer space Treaty, it might be prudent for the United States not actively to oppose but help influence the formulation of appropriate principles with respect to the geostationary orbit within the broad guidelines of the 'common interests' clause. In this connection, the key issue will be how to translate--what the ITU calls--"efficient and economic use" and "equitable access" into more specific legal and technical principles and rules relating to the use of geostationary orbit for--what the Outer space Treaty calls--the "benefit and interests" of all countries. More specifically, the question will be how far is the United States willing to go in accommodating other interests which may be ready to capitalize on any opportunity arising in course of the negotiating process. The situation which may present itself is not entirely without parallel. In the law of the sea negotiations the United States had to draw a line beyond which it felt it could not go in establishing an international regime governing the exploration and exploitation of the resources of the seabed beyond national jurisdiction. 133

Another historical precedent worthy of recalling relates to the negotiations surrounding the Draft Moon treaty in which the 
issue of the proposed regime to govern the exploitation of the resources of the moon and other celestial bodies has been debated for some time. 134 While the differences of opinion may have been narrowed to enable the negotiators to conclude a treaty, the crucial issues of the meaning of common heritage of mankind, the form, authority, composition of the eventual international authority, and the question of what state or group of states is to wield control over it will have yet to be determined in future negotiations.

It should also be borne in mind that there is a substantial difference between the question of obtaining international agreements on geostationary orbit allocation and problems of achieving agreements on the exploitation of resources of the deep sea bed or the moon and other celestial bodies. Utilization of the geostationary orbit has already been underway and the principles of both customary and international treaty law fully support the existing practice from a purely legal point of view. With respect to the law of the sea, exploitation of the deep sea bed appears to have hardly started in any appreciable manner and in relation to the moon and other celestial bodies such exploitation is at present nonexistant. Also, in case of the deep sea bed there is a U.N. General Assembly resolution regarding the exploitation of resources 135 whereas there is no such resolution with respect to the use of geostationary orbit or resources of the moon and other celestial bodies. There is a need to emphasize this because it appears to give the United states a much stronger negotiating posture apart from the 
fact that international support for the U.S. position vis-a-vis the stance of the equatorial countries appears to be much greater if compared to the support for the U.S. position on issues of the deep sea bed or the moon and other celestial bodies.

Notwithstanding the rationale of the foregoing analysis--should it be correct--the history of the last decades appears to be indicative of a growing demand on the part of the Third World countries to champion rights and interests which would provide them with a larger share of the world's material benefits. This demand has found expression in a number of U.N. resolutions such as, for instance, those pertaining to the 'Charter of Economic Rights and Duties of states',136 'Permanent Sovereignty over Natural Resources of Developing Countries 137 and also in the opportune ard frequent reference to the term 'mankind' in such phrases as the 'common heritage of mankind',138 'province of mankind',139 'envoys of mankind', 140 as well as in the increasing invocation of such provision as the 'common interests' clause. 141

The preceding array of considerations appears to suggest that rational policy making cannot afford to ignore the implications of recent trends in the world community. In view of this it may be a circumspect policy for the United States not to close the door to the development of orderly procedures leading to the acceptance of principles and rules governing allocation of the use of geostationary orbit in such a manner that would give recognition to the interests of all countries, including the equatorial countries as well as the space powers, commensurate with their positions. One of the key issues will be to determine on the basis of what criteria 
should such principles and rules be developed so that an acceptable balance can be found for all concerned without impeding advancement. Another closely related issue will be in what ways should the law take into account scientific implications so as to allow for necessary adjustments whenever the technical and scientific criteria change, a situation that can be anticipated to occur with breakthroughs or advances.

While the question of the use of geostationary orbit by satellites and their positioning may come up again at the 1979 WARC as it did in 1977, it may be prudent for the United States to follow the policy of leaving matters of a political and legal nature for consideration of UNCOPUOS and its Legal subcommittee. Nonetheless, a discussion of the formulation of principles governing the use of the geostationary orbit in the Legal subcommittee should be preceded or accompanied by a thoroughgoing study and analysis of the relevant technical and scientific problems by the parent Scientific Subcommittee and appropriate ITU bodies.

\subsection{SPS Development}

The last and perhaps most important key issue to be discussed relates to the option whether or not the United States should internationalize the sPS. With respect to this issue, it would appear that the preparation for consideration by the Legal Subcommittee of guiding principles and procedures governing allocation of the use of geostationary orbit should in no way prevent the United States from simultaneously pursuing other options, particularly the 
taking of global, near-global, regional or bilateral initiatives to pool material and human resources for the development of SPS programs. Under its policy option the United States coild take a positive role in calling for an international pool of resources to help in the assessment of the feasibility, benefits and impediments associated with the developmnet of satellite power systems and eventually assist in the development itself. Such scheme could include participation by all countries in some form through their contributions to natural and human resources needed for the SPS program. Contributions could be taken into account when the eventual benefits would be reaped after the SPS system became operational. This would be to the advantage of all participating countries in that benefits would accrue commensurate to the amount of contributions. Key issues will include the criteria on the basis of which human and material resources will be evaluated and also also the question whether or not the total contribution by a single country or group of countries ought to be the sole factor in determining the distribution of eventual benefits.

In view of the anticipated huge financial outlay required for the development of SPS, it would appear to be in the U.S. interest to have the costs of research and development spread not only domestically between government and private enterprise but also, internationally, among nations of the world. Such policy would appear to reflect both altruism and enlightened self interest in that, on the one hand, solar power as a spatial resource would be used for the benefit of mankind and, on the other hand, the 
international pool would be cost saving and would likely recapture and reemphasize U.S. leadership. An additional advantage of such policy would be that it would further undercut any argument by the equatorial countries that the current system is inequitable inasmuch as the benefits of outer space utilization accrue nnly to the space powers. A disadvantage may be a possible sharing of U.S. control over the SPS, should the United States accept such sharing.

In the implementation of its proposal the United States may conveniently utilize almost all avenues of international cooperation to arrive at an agreement. On the politico-legal level the global approach may be initiated at the United Nations both before the General Assembly and UNCOPUOS and its Legal Subcommittee. With respect to global approach at the technical level, the resources and rich experience of ITU-related bodies should be fully utilized in helping to investigate all relevant aspects of the sPs, including the effects of massive microwave power transmission on radio services. The Technical subcommittee of UnCopuos may provide further input and guidance as necessary.

On a less than global level, the experience of INTELSAT may provide useful insights to draw upon for possible framework. Regional agreements in some regions may be more difficult to negotiate but opportunities for such should be explored especially with the Organization of American States. Insofar as bilateral cooperation is concerned current research agreements on solar energy between the U.S. and other countries 142 could be amended to include cooperation in the development of SPS in whatever form it may be agreed upon. 
An appropriate bilateral agreement may also be considered with the European Space Agency (ESA). Such cooperative project appears quite natural in view of the close U.S.-ESA cooperation in the ShuttleSpacelab project.

Initially, possibly for the next 3-5 years, these agreements could aim mainly at coordinating feasibility studies, including: effects of microwave power transmission on humans and biota as well as on radio services, research of technical problems, determination of appropriate sites for receiving antennas, and meeting of experts and many other matters. Possibly, some of these topics (such as exchange of information, coordination of research) are already covered in current U.S. bilaterals pertaining to solar energy and, to that extent, this may facilitate negotiations. In the conduct of negotiations the United States may wish to proceed on a case-by-case basis taking into account its general relations with the foreign country.

There appears little reason that would prevent the United States from pursuing virtually all of the indicated international avenues simultaneously. Past experience, for instance, in the field of development of international agreements for safeguarding the peaceful utilization of atomic energy, show that the united States entered into many bilateral agreements while it simultaneously championed the establishment of the International Atomic Energy Agency (IAEA) which for many years did not come into existence. 143 
International arrangements on whatever scale (bilateral, multilateral, regional, near-global or global) would appear to give the SPS program a substantial boost both psychologically (prestige-wise) and materially, particularly if developed countries like west Germany and Japan participate. As intimated beforehand, it would also take off the edge of the charge of injustice and inequity advanced by the equatorial countries. Also, once such agreements are negotiated, it is unlikely that countries would create difficulties in relation to the use of geostationary orbit by invoking claims of sovereignty or the 'common heritage' principle or with respect to frequency allocation or perhaps even exposure standards. All in all, a cooperative program on the international level would likely speed up rather than retard the development of the SPS.

Should an international cooperative effort for the development of the SPS prove completely unsuccessful--which appears somewhat unlikely--the United States could still continue its own development program and put its conscience to rest in the firm knowledge that current practices and recognized principles of international law are fully supporting the principle of freedom of use of outer space, that the geostationary orbit area is in outer space, that it is not subject to claims of sovereignty or national appropriation, and that the United States has made a good faith effort to attempt to implement in a concrete manner what has been up to now only a very broad statement of policy, namely the 'common interests' principle. 


\subsection{Time Frames}

There are probably no hard and fast rules for the determination of potential time delays resulting from problems encountered in negotiating international agreements. It would seem, however, that benefits derived from such agreements play a major role in expediting the negotiating process. Problems which may create such delays usually present themselves in the form of some deprivation, actual or potential, which acts as a deterrent and must be counter-balanced by some benefit or a still greater deprivation (actual or potential) in order to serve as an inducement.

Problems and topics of negotiation differ and so do benefits. Accordingly, the nature and type of benefits that can be offered in the negotiating process will ultimately be a major factor in determining the eventual time delays.

On the basis of our analysis of the three assigned areas, it would appear that resolution of the problems in negotiating international agreements on geostationary orbit availability if pursued with a view to achieving a general consensus, including the equatorial countries, is likely to cause the greatest potential time delay, whereas resolution of problems associated with microwave frequency allocation may result in less delay though this is hard to determine because of the competing uses involved and the orbit/spectrum interrelationship.

International acceptance of microwave exposure standards may cause the least delay if technological developments permit the United States to accept the most stringent standards. In the absence 
of such acceptance International Atomic Energy Agency (IAEA) and European Atomic Energy Community studies involving determination of acceptable levels of exposure to atomic radiation may possibly provide some general guidelines for time frame projection. Additionally, the experience of the World Health Organization (wHO) may be reviewed to determine its relevance, if any, in assisting with a reasonable estimate of the anticipated time required to obtain appropriate international agreement on SPS microwave exposure standards.

In all three situations bilateral and multilateral forms of international cooperation in the SPS program through research agreements or otherwise would likely act as a beneficial influence in reducing potential or actual time delays.

Insofar as a more precise projection of time is concerned, it appears that bilateral agreements may take the shortest time as evidenced by past international experience not just in atomic energy but solar energy, outer space and other fields as well. On the basis of a somewhat speculative projection, the conclusion of appropriate bilateral agreements or amendments to already existing agreements should not be expected to take more than 4 years at the most, whereas regional, half- or near-global arrangements not more than 7 years. The latter estimate may appear to be optimistic if compared to the time frame of negotiations relative to the seabed. However, international acceptance or participation in the sps may not run into as many impediments as has the acceptance of an international regime for the seabed. The experience of International Maritime Satellite Organization (INMARSAT) and the IAEA, if comparable, suggest a time frame of about 4 to 7 years. 


\section{RECOMMENDATIONS FOR FURTHER STUDIES}

Recommendations for further studies are listed under two categories: short- and long-term studies. Those listed under short-term studies would appear to have the greatest payoffs if conducted in FY '79, in clarifying or answering key questions identified in previous sections. Those listed under the second category could be undertaken as longer term studies.

\subsection{Short-Term Studies}

A. Formulate alternative proposals setting forth the legal principles and rules governing the use of geostationary orbit within the framework of the Outer space Treaty of 1967. Such proposals should be developed with special regard to priorities and possible new uses of the geostationary orbit, such as SPS operations, and should take into account the need to harmonize the scientific parameters of geostationary orbit and radio spectrum utilization with the overall legal framework.

B. Develop the scientific criteria and parameters of geostationary orbit and radio spectrum frequency utilization in line with legal principles formulated under A., taking account of possible new uses of the geostationary orbit and other scientific developments and innovations.

C. Prepare a survey and analysis of all U.S. solar energy agreements currently in force, including bilateral and multilateral agreements and determine to what extent, if any, would such agreements cover research, exchange of information, training of specialists, meetings of experts and other aspects of the SPS program. 
D. Develop and draft alternative models of international agreements for various phases and aspects of cooperation in the SPS program analysis and development. Such agreements should be prepared for bilateral, regional, half- or near-global and global cooperation and should extend also to cooperative arrangements with appropriate international organizations including, for instance, the European Space Agency. The different types of agreements should encompass appropriate amendments to current solar energy agreements, if necessary, to cover particular aspects of the SPS program. The draft agreements should be geared to various phases (research, development, operation, etc.) and aspects (scientific, economic, political, etc.) of the anticipated SPS program and allow for routine review and/or amendment. They should include feasibility studies, coordination of research, exchange of information and experts, training of scientists, cost analyses, determination of ground sites, orbital locations, frequency use, exposure effects and many other aspects and phases of the SPS program.

\subsection{Long-Term Studies}

A. Prepare a survey and analyze the activities of all international governmental and nongovernmental organizations in the field of solar energy and determine to what extent, if any, could their activities also be extended to phases and aspects of the SPS program without modifications of their basic charters.

B. Develop a U.S. negotiating position and prepare a draft treaty pertaining to microwave exposure standards on the basis of 
the latest U.S. scientific standards under all kinds of situations (accident, sickness and other abnormal situations). The study should take into account the maximum and minimum negotiating positions with special regard to what can be achieved under current or near-term SPS-technology and the effects that more stringent exposure standards may have on value losses (costs and other considerations). The assessment of the U.S. negotiating position should include a projected listing of whatever hard choices may have to be made between competing values and preferences.

C. An additional area for study would be to assess the problems to be encountered and the best ways of overcoming them in the effort to enlist the support of international nongovernmental and governmental organizations for the SPS. This study should include a consideration of the relevant activities of these organizations and the extent and ways in which these organizations and their activities would be effected by the SPS. The study should examine the benefits expected to be derived from the SPS and point out some of the hard choices that may have to be made especially with respect to priorities. 


\section{FOOTNOTES}

1. PRC Systems Sciences Co., Statement of Work, May 1978.

2. For a brief review of possible uses of geostationary orbit, see U.N. General Assembly, Committee on the Peaceful Uses of Outer Space, Physical Nature and Technical Attributes of the Geostationary Orbit, Study Prepared by the Secreatariat, Doc. A/AC.105/ 203, Section 5 (1977).

3. There has been a steadily growing literature on the subject. See, for instance, C.E. Bloomquist, A Survey of Satellite Power Stations, PRC Systems Sciences Co., (PRC R-1844, Sept., 1976); Boeing Aerospace Co., Solar Power Satellite - System Definition study, 2 vols. Part I and Part II, Vol. I (D 18022876-1, Cont. No. NAS9-15196, Dec. 1977); ECON Inc., Political and Legal Implications of Developing and operating a Satellite Power System, Final Report (77-195-1, August 15, 1977); P.E. Glaser, Development of the Satellite Solar Power Station, in J. Grey (ed.), Space Manufacturing Facilities (Space Colonies) 115 (Am. Inst. Aeronautics \& Astronautics, 1977); P.E. Glaser, Solar Power Satellite Development Program, in R.A. Van Patten and others (eds.), Advances in the Astronautical Sciences, Vol. 36 (1977) Pt. 1, The Industrialization of Space 454 (Am. Astronautical Society, 1978); S. Gorove, Studies in Space Law: Its Challenges and Prospects at 205ff, (1977); International Technical Services, Inc. An Overview of Prospective Organizational structures in the solar Power Satellite Field, Draft Report. For Task II, Subtask 2: Roles of Governmental Entities (Cont. No. 31-109-38-4387, June 30, 1978); G.K. O'Neill, The High Frontier: Human Colonies in Space (1977).

4. J.J. Gehrig, Geostationary Orbit--Technology and Law, Proc. 19 th Colloquium on the Law of Outer Space 267 at 268, (1977).

5. ECON Inc., Political and Legal Implications of Developing and Operating a Satellite Power System, Final Report, at p. 60, (77-195-1, August 15, 1977). The fundamental limit to the utilization of the geostationary orbit is the mutual interference generated by satellite networks. For an analysis, see M.I. Jeruchim, A Survey of Interference Problems and Applications to Geostationary Satellite Networks, 65 Proc. Inst. Electrical \& Electronics Engineers 317 (1977).

6. Op.cit., supra note 2 , at Sec. $3(\mathrm{~b})$.

7. Table of Artificial Satellites Launched in 1977, 45 Telecommunication J. (Supplement, April 1978).

8. Op.cit., supra note 2 at Sec. 4 .

9. Op.cit., supra note 4 . 
10. According to D.J. Withers saturation could be delayed for a long period if various practices and principles of system design and use were internationally agreed upon and applied. See D.J. Withers, Effective Utilization of the Geostationary orbit for Satellite Communication, 64 Proc. Inst. Electrical \& Electronics Engineers 308 (1977).

11. International Telecommunication Convention of Oct. 25, 1973, Malaga-Torremolinos, Art. 33(2), T.I.A.S. 8572 .

12. ECON Inc., Political and Legal Implications of Developing and Operating a Satellite Power System, Final Report (77-195-1, August 15, 1977).

13. Id. at 48 .

14. For a review of early theories, see $\mathbf{S}$. Gorove, studies in Space Law: Its Challenges and Prospects at 14ff, (1977).

15. Treaty on Principles Governing the Activities of States in the Exploration and Use of Outer Space, Including the Moon and other Celestial Bodies (hereinafter re Space Treaty") was signed on January 27, 1967 and entered into force October 19, 1967, 18 U.S.T. 2410, T.I.A.S. 6347 .

16. M.S. McDougal, The Emerging Customary Law of Spacc, $53 \mathrm{Nw}$. U.L. Rev. 618 (1964).

17. For a discussion of these claims, see infra section 3.1 .3 .

18. Gorbiel, The Legal Status of Geostationary Orbit: Some Remarks, 6 J. Space L. (in the press, 1978).

19. Art. 1, par. 2 .

20. Id., par. 1 .

21. S. Gorove, Freedom of Exploration and Use in the Outer Space Treaty, I Denver J. Int'I L. and Pol. 93 at 104 (1971).

22. Id. at $101 \mathrm{ff}$.

23. Op cit., supra note 12 at 48 .

24. A.A. Cocca, Towards an Adequate Legal Regulation of the Geostationary Orbit, Proc. of the Twentieth Colloquium on the Law of Outer Space 193 at 194 (1978).

25. Ibid. 
26. S. Gorove, Interpreting Article II of the Outer Space Treaty 37 Fordham L. Rev. 349 at 352. (1969). A recently concluded study argues that 30 years would not be "permanence" to constitute appropriation. This, however, is somewhat doubtful. See supra note 12 at 57 .

27. For a discussion, see infra sec. 3.1.3.1.

28. See comment by Professor Goedhuis in the Report of the 54 th Conference of the International Law Association 427 (1971).

29. S. Gorove, Studies in Space Law: Its Challenges and Prospects at 217 , (1977).

30. Supra note 13 .

31. Doc. A/C.1/PV.10, Pp. 37-38, 81-82.

32. Brazil was represented by an observer.

33. For an English translation of the Declaration, see infra Appendix.

34. Bogota Declaration, Sect. 1 .

35. Id., Sect. $3(d)$.

36. Id., Sect. 3(e).

37. Id., Sect. 3(c).

38. Id., sect. $3(\mathrm{~b})$.

39. Id., sect. I.

40. Id., Sect. 1 .

41. Id., Sect. 4 .

42. Id., Sect. 4 .

43. Id., sect. 4 .

44. Id., Sect. 4 .

45. Id., Sect. 4 .

46. DoC. A/AC.105/C.2/7/Add. 1 (1978).

47. DOC. A/AC.105/C. 2. SR. 296, p. 3 (1978).

48. Press Release OS/222, April 3, 1978, p. 2. 
49. DOC. A/AC.105/C.2. SR.296, p.3 (1978).

50. Id. at p. 4 .

$51 \quad$ Ibid.

52. Ibid.

53. Press release OS/852, April 5, 1978, p. 2 .

54. Doc. A/AC.105/C.2/SR.298, April 6, 1978, pp. 5-6.

55. Press release OS/852, April 5, 1978, p. 2 .

56. Id., p. 2.

57. Id., p. 3 .

58. Press release OS/224, April 5, 1978, p. 3.

59. Press release os/852, April 5, 1978, p. 3.

60. Press release OS/223, April 4, 1978, p. 5.

61. Id. p. 4 .

62. Id., p. 3 .

63. Id., p. 2 .

64. Supra note 54 .

65. Ibid.

66. Ibid.

67. Supra note 59.

68. Ibid.

69. Supra note 54 .

70. Ibid.

71. Supra note 55 .

72. Supra note 58 .

73. Supra note 54 .

74. Bogota Declaration, Sect. 1 .

75. Id., sect. 1 .

76. Id., Sect. $3(a)$. 
77. Doc. A/AC.105/C.2/SR.296, April 4, 1978, pp. 2-3.

78. Press release OS/222, April 3, 1978, p. 2.

79. Id., p. 11 .

80. Supra note 55 at p. 1 .

81. Doc. A/AC.105/218, April 13, 1978, p. 10.

82. Supra note 77 at p. 5 .

83. Ibid.

84. Ibid.

85. Supra note 54, p. 6 .

86. Supra note 55 .

87. Supra note 54 .

88. A/AC.105/C.2/SR.290, March 23, 1978, p. 5.

89. Supra note 59 .

90. Ibid.

91. Supra note 89 .

92. Supra note 60 .

93. Press release 0S/844, March 17, 1978, p. 3 .

94. Supra note 60 at p. 4.

95. Supra note 59 .

96. Existence of the principle which is reflected in state practice, has been acknowledged by the delegate of Columbia. Supra note 77 at p. 4 .

97. Final Acts of the World Administrative Radio Conference for Space Telecommunications, Res. Spa. 2-1 (Geneva, 1971).

98. Id., Res. Spa. 2-1.

99. Id., Res. Spa. 2-2.

100. Id., Partial Revision of the Radio Regulations, Art. 9A.

101. International Telecommunications Convention of Oct. 25, 1973, Malaga-Torremolinos, Art. 33, T.I.A.S. 8572 . 
102. Id., Art. 35.

103. Id., Art. $10(3)$.

104. Final Acts of the World Administrative Radio Conference for the Planning of the Broadcasting Satellite Services in Frequency Bands 11.7-12.2 GHz (in Regions 2 and 3 ) and 11.7-12.5 GHz (in Region 1), Res. No. Sat-7 (Geneva, 1977).

105. Ibid.

106. U.S. Dept. State, Report of the U.S. delegation to the WARC-BS (40 TD. Ser. No. 80, 1977).

107. Final Protocol No. 51 .

108. Id., No. 2 .

109. Id.., No. 74 .

110. See Raytheon Co., Microwave Power Transmission System Studies, vol. 1, p. 4 (NASA Lewis Res. Center, CR-134886); NASA \& Department of Energy, Satellite Power System (SPS) Concept Development and Evaluation Program Plan, July 1977August 1978, p.6 (1978). Most of the development of technology for microwave power transmission in free space has been carried out in the 2400 to $2500 \mathrm{MH}$ band. See Frequency Assignment requirements for Free Space Transmission by Microwave Beam with Particular Reference to Satellite Solar Power for Use on Earth, b. I-1 (Supporting material for an informal briefing given to the FCC on 3 llay 1977 by the Raytheon Company in association with Arthur D. Little and representatives from other companies.)

For a discussion of the environmental affect of microwave power transmission, see C.E. Bloomquist, A Survey of Satellite Power Stations 155-168, 201-207 (PRC Systems Sciences Co., R-1844, Sept., 1976).

111. International Telecommunication Convention of Oct. 25, 1973, T.I.A.S. 8572 .

112. Id. Art. 4 .

113. United Nations, Dept. of Political and Security Council Affairs, Space Activities and Resources, Doc. A/AC.105/193, P. 41 (1977).

114. The Random House Dictionary of the English Language 1326 (1966). 115. F.G. Stremler, Introduction to Communications Systems 3 (1977). 116. 11. Overman, Understanding Telecommunications 3 (1974). 
117. Op. cit. supra note 113 at 38 . 'Harmful interference' is defined as "Any emission, radiation, or induction which endangers the functioning of a radio navigation service used permanently or temporarily for the safeguarding of human life and property or seriously degrades, obstructs, or repeatedly interrupts a radio communication operated in accordance with the Radio Regulations." See Annex 2 to the ITC.

118. Ibid.

119. This conclusion is also supported by unofficial views of ITU functionaries, especially in the IFRB, expressed in the course of interviews conducted in the summer of 1978.

120. The IFRB procedure has been summed up in the following description:

1. Countries proposing to establish a telecommunication satellite system are required, at least five years before the system is brought into use, to notify the International Frequency Registration Board (IFRB) of all the detailed characteristics of the system itself and its satellites (including data on the orbit). Members of ITU, who are kept informed by means of the circulars regularly published by IFRB, can thus protect their interests and co-ordinate their space radio-communications with regard to the position of a satellite in the geostationary satellite orbit. 2. After notification of the use of a frequency assignment by a space station and technical examination of the notice by IFRB, and depending on the Board's findings, the assignment is recorded in the Master Frequency Register. The entry consists of a date in column 2 and a symbol indicating the Board's findings in column 13. In accordance with Article 10 of the International Telecommunication Convention (Malaga-Torremolinos, 1973) the purpose of recording the assignment is to give it formal international recognition. That means that it has to be taken into consideration by other administrations when planning new satellite network projects and by IFRB when examining notices received subsequently, under the terms of the Radio Regulations.

See J. Busak, The Geostationary Satellite Orbit:International Cooperation or National Sovereignty?, 45 Telecommunication J. 167 at 168 (April 1978).

121. Solar Satellite Power System Concepts: Hearings Before the Subcomm. on Space Science and Application and the Subcomm. on Energy, Research Development and Demonstration of the House Comm. on Science and Technology, 94th Cong., 2nd Sess. 370 (Comm. Print, 1976). 
122. For a table of distance from the beam's center, see C.E. Bloomquist, A Survey of Satellite Power Stations 163 (PRC Systems Sciences Co. 4-1844, Sept., 1976).

123. P.E. Glaser, Solar Power from Satellites, Physics Today 30 at 37 , (Feb. 1977).

124. Op. cit. supra note 122 at 162 .

125. Supra note 123 .

126. Ibid.

127. Art. IX.

128. Op. cit. supra note 122 at 205 .

129. CCIR, XIVth Plenary Assembly, Kyoto, 1978: Draft Report, Characteristics and Effects of Radio Techniques for the Transmission of Energy from Space, Doc. 2/289 (Jan. 25, 1978).

130. Ibid.

131. S.K. Sarkar, Geostationary Orbital Positions For Space Stations, Proc. 20th Colloquium on the Law of Outer space 450 (1978).

132. Op. cit. supra note 113 at pp. 54 and 58 .

133. For a brief recent assessment of some of the unresolved issues of the Law of the Sea Conference, see E.L. Richardson, Oceans: Law of the Sea Conference, 78 Dept. St. Bull 47 (1978).

134. S. Gorove, Studies in Space Law: Its Challenges and Prospects $167 \underline{\mathrm{ff}}$. (1977).

135. Res. 2467 A (XXIII).

136. Res. $3281(\mathrm{XXIX)}$.

137. Res. 2692 (XXV).

138. See, for instance, the Bogota Declaration.

139. Outer Space Treaty, Art. I.

140. Id., Art. V. 
141. Id., Art. I.

142. For a concise review of U.S. International cooperative activities including bilateral and multilateral agreements, in the field of solar energy, see 1979 Dept. of Energy Authorization: Hearings on Advanced Energy Technologies and Energy Conservation before the Subcomm. on Advanced Energy Technologies and Energy Conservation, Research Development and Demonstration. of the House Comm. on Science and Technology, 95th Cong. 2nd Sess., vol. 5, p. $286 \underline{\text { ff. }}$

For a summary of UNESCo's activities in the same field, see Solar Energy Research and Development: Hearings on S. 2819 and S. 3234 before the Joint Comm. on Atomic Energy, 93rd Cong., 2nd Sess. 575ff. (1974).

143. For details and references, see S. Gorove, Controls over Atomos-For-Peace: Some Facts and Implications for Nuclear Disarmament, 27 La. L. Rev. 36 (1966). 


\section{BIBL IOGRAPHY}

\section{A. Official Publications \\ (Domestic)}

1. Congress

1979 Department of Energy Authorization: Hearings on Advanced Energy Technologies and Energy Conservation before the Subcomm. on Advanced Energy Technologies and Energy Conservation, Research, Development and Demonstration at the House Comm. on Science and Technology, 95th Cong. 2nd Sess., Vol. 5 (1978).

Future Space Programs, Hearings before the House Comm. on Science and Technology, 95th Cong., 2nd Sess. (Comm. Print, 1978).

1978 NASA Authorization: Hearings on H.R. 2221 before the Subcomm. on Space Science and Applications of the House Comm. on Science and Technology, 95th Cong., lst Sess., Vol. I, Pt. 3 (1977) .

NASA Authorization for Fiscal Year 1978: Hearings on S. 365 before the Subcomm. on Science, Technology, and space of the Sen. Comm. on Commerce, Science, and Transportation, 95th Congress, lst Session, Part 2 (1977).

Solar Power From Satellites, Hearings before the Subcommittee on Aerospace Technology and National Needs of the Senate Committee on Aeronational and Space Sciences, 94th Congress 2d Session (Jan. $19 \& 21,1976)$.

Solar Satellite Power System Concepts: Hearings Before the Subcomm. on Space Science and Application and the Subcomm. on Energy, Research Development and Demonstration of the House Comm. on Science and Technology, 94th Cong., 2nd Sess. (Comm. Print, 1976). 
Solar Energy Research and Development: Hearings on S. 2819 and S. 3234 before the Joint Comm. on Atomic Energy, 93rd Cong. 2nd Sess. (1974).

Space Shuttle Payloads: Hearings on Candidate Missions for the Space Shuttle before the Senate Committee of Aeronautical and Space Sciences, 93rd Cong. 1st Sess., Part 2 (1973).

2. Dept. of Energy

Dept. of Energy, Guide to Solar Energy Programs (DOE/ET-0036, March 1978).

(Contracted studies are listed under the names of authors or companies who prepared them.)

3. NASA

NASA, Aeronautics and Space Report of the President: 1976 Activities (1976).

NASA, Initial Technical, Environmental, and Economic Evaluation of Space Solar Power Concepts 2 vols., JSC-11568, Aug. 31, 1976).

NASA \& Dept. of Energy, Satellite Power System (SPS) Concept Development and Evaluation Program Plan July 1977 - August 1978 (Feb., 1978).

(Contracted studies are listed under the names of authors or companies who prepared them.)

\section{B. Official Publications \\ (International)}

International Telecommunication Union

Broadcasting Satellite Conference, Doc. 81-E Annex 4, Jan. 17, 1977 (contains the English translation of the Bogota Declaration of Dec. 3, 1976) 
Fifteenth Report by the International Telecommunication Union on Telecommunication and the Peaceful Uses of Outer Space, (1976); Fourteenth Report (1975); Thirteenth Report (1974) .

Final Acts of the 1971 World Administrative Radio Conference for Space Telecommunications, 23 U.S.T. 1527, T.I.A.S. 7435 .

Final Acts of the 1977 World Administrative Radio Conference for the Planning of the Broadcasting-Satellite Service in Frequency Bands 11.7-12.2 GHz (in Regions 2 and 3 ) and $11.7-12.5 \mathrm{GHz}$ (in Region 1), Geneva, 1977.

International Frequency Registration Board, Weekly Circulars and its special sections.

International Radio Consultative Committee (CCIR), Study Groups, Special Preparatory Meeting (WARC-1979), Doc. P/61-E (29 May 1978). International Telecommunication Convention of Oct. 25,1973 Malaga-Torremolinos, T.I.A.S. 8572 .

Radio Regulations (1976 ed.).

United Nations.

Dept. of Political and Security Council Affairs, Space Activities and Resources, Doc. A/AC.105/193 (1977).

General Assembly, Committee on the Peaceful Uses of Outer Space, Physical Nature and Technical Attributes of the Geostationary Orbit, Study Prepared by the Secreatariat, Doc. A/AC.105/203 (1977) .

General Assembly, Committee on the Peaceful Uses of Outer Space, Report of the Scientific and Technical Sub-Committee on the Work of its Fourteenth Session Doc. A/AC.105/195, (1977).

General Assembly, Committee on the Peaceful Uses of Outer Space, Report of the Scientific and Technical Sub-Committee on the Work of its Fifteenth Session Doc. A/AC.105/216, (1978). 
General Assembly, Committee on the Peaceful Uses of Outer Space, Report of the Legal Sub-Committee on the Work of its Sixteenth Session, March 14- April 8, 1977, Doc. A/AC.105/196, (1977).

General Assembly, Committee on the Peaceful Uses of Outer Space, Report of the Legal Sub-Committee on the Work of its Seventeenth Session, March 13- April 7, 1978, Doc. A/AC.105/218 (1978).

General Assembly, Committee on the Peaceful Uses of Outer Space, Report to the General Assembly, (Supplt., in print, 1978). (See also Summary Records of meetings and Press Releases cited in the annotations.)

\section{Books, Monographs, Treatises}

S. Baranski \& P. Czerski, Biological Effects of Microwaves (1976).

C.E. Bloomquist, A Survey of Satellite Power Stations, (PRC Systems Sciences Co., R-1844, Sept., 1976).

Boeing Aerospace Co., Solar Power Satellite - System Definition Study, 2 vols. Part I and Part II, Vol. 1 (D 180-22876-1, Cong. No. NAS9-15196, Dec. 1977).

S. Brown, N.W. Cornell, L.L. Fabian \& E.B. Weiss, Regimes for the Ocean. Outer space and Weather (1977).

ECON Inc., Political and Legal Implications of Developing and Operating a Satellite Power System, Final Report (77-195-1, August 15, 1977). 
S. Gorove, Studies in Space Law: Its Challenges and Prospects (1977).

J. Grey, Space Manufacturing Facilities (Space Colonies), (Am. Inst. of Aeronautics, 1977).

R. D. Johnson, (ed.), Space Settlements - A Design Study (NASA, 1977).

D. M. Leive, The Future of the International Telecommunication Union (Am. Soc'y Int'l L., Studies in Transnational Legal Policy, No. 3, 1972).

D. 11. Leive, International Telecommunications and International Law: The Regulation of the Radio Spectrum (1970).

N. Matte \& M. M. Tatte (eds.) Telésat, Symphonie et la Cooperation Spatiale Régionale (1978).

M. S. McDougal, H. Lasswell and I. Vlasic, Law and Public Order in Space (1962).

G. K. O'Neill, The High Frontier: Human Colonies in Space (1977) .

M. Overman, Understanding Telecommunications (1974). Raytheon Co., Microwave Power Transmission System Studies, 2 vols. (NASA CR-134886, ER75-4368, Dec., 1975).

L. E. Schwartz, International organizations and Space Cooperation, (1962).

D. Smith, Communications via Satellite: A Vision in Retrospect (1976).

D. Smith, International Telecommunications Control (1970). F. G. Stremler, Introduction to Communication Systems (1977). 
R.A. Van Patten, P. Siegler \& E.V.B. Stearns (eds.), Advances in the Astronautical Sciences Vol. 36, Pt. 2: The Industrialization of Space (Proc. 23rd Am. Astronautical Soc'y Annual Meeting, Oct. 18-20, 1977; AAS, 1978).

E. McWhinney (ed.), The International Law of Communications (1971).

D. Articles, Comments, Papers, Reports, Statements, etc.

H. Berger, International Law and Solar Energy Satellites, Proc. 20th Colloquium on the Law of Outer space 149 (1978).

J. Busak, The Geostationary Satellite Orbit - International Cooperation or national Sovereignty?, 45 Telecommunication J. 167 (April 1978).

R.E. Butler, World Administrative Radio Conference for Planning Broadcasting Satelite Service, 5 J. Space L. 93 (1977).

W.C. Brown, Transmission of Power from Space to Earth, A Paper Presented at AIAA-EEI-IEEE Sponsored Conference on "New Options in Energy Technology" (San Francisco, Aug. 2-4, 1977).

R. Caputo and T. English, Approach to Identifying Environmental Questions Related to the SPS, Presented at JSC, Houston, Texas, June 3, $1976(\mathrm{TE}-1$, June 1976).

L.R. Caruso and L. Caruso, International Cooperation in the Production of Solar Energy Through the Use of Satellites, 9 Law. of the Americas 540 (1977).

A.A. Cocca, The Geostationary Orbit, Focal Point of space Telecommunication Law, 45 Telecommunication J. 171 (April 1978).

A. A. Cocca, Towards an Adequate Legal Regulation of the Geostationary orbit, Proc. of the Twentieth Colloguium on the Law of Outer Space 193 (1978). 
R. Colino, International Cooperation Between Communication Satellite by Laws: An Overview of Current Practices and Future Prospects, 5 J. Space L. 65 (1977).

Comment, The Role of the International Telecommunication Union in the Settlement of Harmful Interference Disputes, 13 Columbia v. Transnational I. 82 (1974).

Comment, Utilization of the Geostationary Orbit -- A Need for Orbital Allocation, 13 Columbia J. Transnat'l L. 98 (1974). B.H. Dickson, Effects of 1977 I.T.U. World Administrative Radio Conference on the Formulation of U.N. Draft Principles on Direct Broadcast Satellites, 2 Annals Air Space L. 255 (1977).

I.H.Ph. Diederiks-Verschoor and E. Galloway, Introduction, Proc. 20 th Colloquium on the Law of Outer Space 1 (1978).

S. Doyle, INMARSAT: The International Maritime Satellite Organization: Origins and Structure, 5 J. Space L. 45 (1977). B.G. Dudakov, International Legal Problems on the Use of Geostationary Orbit, Proc. 19th Colloquium on the Law of Outer Space 406 (1977).

E. Fasan, Utilization of Energy from Space - Some Legal Questions: Introductory Report, Proc. 18th Colloquium on the Law of Outer Space 2 (1976).

M.A. Ferrer, The Use of Geostationary Orbit, Proc. 20th Colloquium on the Law of Outer Space 216 (1978).

E.R. Finch, Jr., The Geostationary Orbit and 1967 outer Space Treaty, Proc. 20th Colloquium on the Law of Outer Space 219 (1978).

E. Galloway, Present Status in the United Nations of Direct Broadcast Satellites (June, 1977), 2 Annals Air and Space L. 269, (1977). 
J. Galloway, Telecommunications, National Sovereignty and the Geostationary Orbit, Proc. 20th Colloquium on the Law of Outer Space 226 (1978).

J.J. Gehrig, Geostationary Orbit--Technology and Law, Proc. 19th Colloquium on the Law of Outer Space 267 (1977).

P.E. Glaser, Development of the Satellite Solar Power Station, in J. Grey (ed.), Space Manufacturing Facilities (Space Colonies) 115 (Am. Inst. Aeronautics \& Astronautics, 1977).

P.E. Glaser, Solar Power from Satellites, Physics Today 30 (Feb. 1977).

P.E. Glaser, Solar Power Satellite Development Program, in R.A. Van Patten \& Others (ed.), Advances in the Astronautical Sciences, Vol. 36 (1977) Pt. 1, The Industrialization of Space 454 (Am. Astronautical Society, 1978).

P.E. Glaser, Statement on the "Development of the Satellite Solar Power Station" in Hearing before the Subcomm. on Space Science and Applications and the Subcomm. on Energy Research, Development and Demonstration of House Comm. on Science and Technology on "Solar Satellite Power Concepts," 94 th Cong., 2d Sess. (Comm. Print, Feb. 20, 1976).

P.E. Glaser, Statement on "Satellite Solar Power, Economic and Social Implications, 1978 IJASA Authorization: Hearings on H.R. 2221 before the House Comm. of Science and Technology, 95th Cong., lst Sess. Vol. III, 466 (1977).

J.H. Glazer, Domicile and Industry in Outer Space, 17 Columbia J. Transnat'l L. 67 (1978). 
H. Gorbiel, The Legal Status of Geostationary orbit: Some Remarks, 6 J. Space Law (in print, 1978).

S. Gorove, Freedom of Exploration and Use in the Outer Space Treaty, I Denver J. Int'l L. and Pol. 93 (1971).

S. Gorove, Interpreting Article II of the Outer Space Treaty 37 Fordham L. Rev. 349 (1969).

International Technical Services, Inc., An Overview of Prospective Organizational Structures in the Solar Power Satellite Field, Draft Report for Task I, Subtask 3 (Cont. No. 31-109-38-4387, June 30, 1978); also Final Report for Task I (July 17, 1978), same cont. no.

International Technical Services, Inc., An Overview of Prospective Organization Structures in the Solar Power Satellite Field, Draft Report. For Task II, Subtask 2: Roles of Governmental Entities (Cont. No. 31-109-38-4387. June 30, 1978).

H.K. Jacobson, International Institutions for Telecommunications: The ITU's Role, in E. McWhinney, The International Law of Communications (1971).

M.I. Jeruchim, A Survey of Interference Problems and Applications to Geostationary Satellite Networks, 65 Proc. Inst. Electrical \& Electronics Engineers 317 (1977).

D.R. Justesen, H.A. Ragan, L.E. Rogers, A.W. Guy, D.L. Hjersen, W.T. Hinds and R.D. Phillips, Compilation and Assessment of Microwave Bioeffects: Survey of Pertinent Literature, Research Needs and Bibliography (A0-02-01/EA81028, Batelle, Pacific Northwest Laboratories, Dec. 1977). 
W. von Kries, The Legal status of the Geostationary Orbit: Introductory Report, Proc. 18 th Colloquium on the Law of Outer Space 27 (1976).

M. Markoff, The International Space Agency Project, the Bogota Declaration and the Common Interests Rule, Proc. 20 th Colloquium on the Law of Outer Space 29 (1978).

R.B. Marsten, Satellites and Space Communication, 45 Telecommunications J. 305 (1978).

M.S. McDougal, The Emerging Customary Law of Space, $58 \mathrm{Nw}$. U.L. Rev. 618 (1964).

M. Menter, Legal Implications of Commercial Utilization of Space, Proc. 20th Colloquium on the Law of Outer Space 334 (1978).

M. Mili, World Administrative Radio Conference for the Planning of the Broadcasting - Satellite Service in Frequency Bands 11.7$12.2 \mathrm{GHz}$ (in Regions 2 and 3 ) and $11.7-12.5 \mathrm{GHz}$ (in Region 1) Proc. 20th Colloquium on the Law of Outer Space 346 (1978). A.L. Moore, Direct Broadcast Satellites by Treaty or Regulation: The Committee on Peaceful Uses of Outer Space v. the ITU, Proc. 19th Colloquium on the Law of Outer Space 341 (1977).

R.H. Moss, Legal Considerations on the Development and Use of Satellite Solar Power Stations, Proc. 20 th Colloquium on the Law of Outer Space 374 (1978).

James $\mathrm{T}$. Murphy, Statement, in 1978 NASA Authorization: Hearings on H.R. 2221 before the Subcomm. on space science and Applications of the House Comm. on Science and Technology, 95 th Cong., lst Sess. Vol. I, Part 2, 702 (1977). 
G.K. O'Neill, Testimony, in Hearings on Solar Power from Satellites on Aerospace Technology and National Needs before the Sen. Comm. on Aeronautical and Space Sciences, 94 th Cong., 2nd Sess. (1978).

L. Perek, Physics, Uses and Regulation of the Geostationary Orbit, or, Ex Facto Lex. Proc. 20th Colloquium on the Law of Outer Space 400 (1978).

R. Piland, testimony, on "Space Solar Power Status", in 1979 NASA Authorization: Hearing on H.R. 10664 before the Subcomm. on Space Science and Applications of the House Comm. on Science and Technology, 95th Cong., 2nd Sess., Vol. 1, Pt. 2, 1849 (1978).

W.B. Pritchard, Satellite Communication--An Overview of the Problems and Programs, 65 Proc. Inst. Electrical \& Electronics Engineers 294 (1977).

H. Reis, Testimony, in Hearings on "International Space Law" before the Subcomm. on Space Science and Applications of the House Comm. on Science and Technology, 94 th Cong. 2nd Sess. 26 (1976).

S.K. Sarkar, Geostationary Orbital Positions for Space Stations, Proc. 20th Colloquium on the Law of Outer Space 250 (1977).

S.K. Sarkar, Space Operations and Radio Regulations: ways to Coordinate Space Science and Technology with Space Law, Proc. 20th Colloquium on the Law of Outer Space 112 (1978).

M.A. Stull and G. Alexander, Passive Use of the Radio Spectrum of Scientific Purposes and the Frequency Allocation Process, $43 \mathrm{~J}$. Air L. and Commerce 459 (1977). 
D.J. Withers, Effective Utilization of the Geostationary

Orbit for Satellite Communication, 65 Proc. Inst. Electrical \& Electronics Engineers 308 (1977).

T.E. Wolcott, Sovereignty and Outer Space: Spatial flusions, Proc. 20th Colloquium on the Law of Outer Space 486 (1978).

D. Woodcock, Closed Brayton Cycle Turbines for Satellite Solar Power Stations, in Grey (ed.), Space Manufacturing Facilities, (Space Colonies) 129 (Am. Inst. Aeronautics \& Astronautics, 1977).

76 
Representatives of the states situated on the Equator met in Bogota, Republic of Colombia, from 29 November to 3 December 1976 for the purpose of studying the situation with regard to the geostationary orbit corresponding to their national land, sea, and island territory, considered as a natural resource. After an exchange of information and having studied in detail the different technical, legal and political aspects involved in the exercise of national sovereignty by States over this orbit, they reached the following conclusions:

\section{The geostationary orbit as a natural resource}

The geostationary orbit is a circular orbit in the equatorial plane in which the period of sidereal revolution of the satellite is equal to the period of sidereal rotation of the Earth and the satellite moves in the same direction as the Earth's rotation. When a satellite describes this particular orbit, it is said to be geostationary; such a satellite appears to be stationary in the sky when viewed from the earth, and is fixed at the zenith of a given point on the Equator, whose longitude is by definition that of the satelite.

This orbit is located at an approximate distance of $35,871 \mathrm{~km}$ above the Earth's Equator.

The equatorial countries declare that the synchronous geostationary orbit is a physical fact arising from the nature of our planet, because its existence depends exclusively on its relation to gravitational phenomena caused by the Earth, and that for that reason it must not be considered part of outer space. Therefore, the segments of the synchronous geostationary orbit are an integral part of the territory over which the equatorial states exercise their national sovereignty. The geostationary orbit is a scarce, natural resource whose importance and value is increasing rapidly with the development of space technology and with the growing need for communication; therefore, the equatorial countries meeting in Bogota have decided to proclaim and defend on behalf of their peoples the existence of their sovereignty over this natural resource. The geostationary orbit represents a unique facility which it alone can offer for telecommunication services and other uses requiring geostationary satellites.

The frequencies and orbit of geostationary satellites are natural resources fully accepted as such under the current rules of the International Telecommunication Union. Technological progress has caused a continuous increase in the number of satellites using this orbit, which could lead to saturation in the near future.

*For a text of the Declaration, see EL ESPECTADOR (Columbia), December 7, 1976, p. 13A. For the English translation, see ITU, Broadcasting Satellite Conference, Doc. No. 81-E (Jan. 17, 1977), Annex 4. 
The solutions proposed by the International Telecommunication Union in the relevant documents with a view to achieving a better use of the geostationary orbit and preventing its imminent saturation are at present impracticable, and are also unfair, because they would considerably increase the cost of utilizing this resource, especially for developing countries. Such countries do not have the same technological and financial resources as industrialized countries, which enjoy an evident monopoly in the exploitation and use of the synchronous geostationary orbit. In spite of the principle established by Article 33, paragraph 2, of the 1973 International Telecommunication Convention, that in using frequency bands for space radio services, Members shall bear in mind that radio frequencies and the geostationary satelite orbit are limited natural resources and that they must be used efficiently and economically so as to allow equitable access to this orbit and to its frequencies, we can see that both the geostationary orbit and the frequencies have been used in a way that does not allow equitable access to the developing countries, which do not have the technical and financial means that the great Powers have. Therefore, it is essential for the equatorial countries to state their determination to exercise their sovereignty over the corresponding segments of the geostationary orbit.

\section{Sovereignty of equatorial states over the corresponding segments} of the geostationary orbit

In describing this orbit as a natural resource, the equatorial States reaffirm "the right of peoples and nations to permanent sovereignty over their natural wealth and resources, which must be exercised in the interest of their national development and of the well-being of the people of the State concerned", as stated in Resolution 2692 (XXV) of the United Nations General Assembly, entitled "Permanent sovereignty over natural resources of developing countries and expansion of domestic sources of accumulation for economic development".

Furthermore, the Charter of Economic Rights and Duties of States solemnly adopted by the United Nations General Assembly in Resolution 3281 (XXIX) once more confirms the existence of a sovereign right of states over their natural resources, in Article 2, paragraph 1, which reads: "Every state has and shall freely exercise full permanent sovereignty, including possession, use and disposal, over all its wealth, natural resources and economic activities".

The above-mentioned provisions lead the equatorial states to affirm that the synchronous geostationary orbit, being a natural resource, is under the sovereignty of the equatorial states.

\section{Legal status of the geostationary orbit}

Bearing in mind the existence of sovereign rights over the segments of the geostationary orbit, the equatorial countries consider that the legal system applicable in this area must take into account the following: 
a) The sovereign rights put forward by the equatorial countries are directed towards rendering real benefits to their respective peoples and to the world community, in complete contrast to the present state of affairs, in which the orbit is used primarily for the benefit of the most developed countries.

b) The segments of the orbit corresponding to the areas of the high seas beyond the national jurisdiction of States shall be considered as the common heritage of mankind. Consequently, the competent international agencies may regulate their use and exploitation whenever that is for the benefit of mankind.

c) The equatorial states do not object to free orbital transit or the transit of communications requiring satellites covered and authorized by the International Telecommunication Convention, when these satellites pass through their space territory in gravitational flight outside their geostationary orbit.

d) Devices to be placed in a fixed position on an equatorial State's segment of the geostationary orbit shall require previous and express authorization on the part of the State concerned, and the operation of the device shall be governed by the national law of that state. It is to be understood that this authorization is different from the coordination requested in cases of interference among satellite systems, as specified in the Radio Regulations. The authorization in question clearly relates to countries' right to allow the operation of fixed radio stations within their territory.

e) The equatorial states do not acquiesce in the presence of satellites on their segments of the geostationary orbit and declare that the existence of such satellites does not confer any right to place satellites there or to use the segment unless expressly authorized by the state exercising sovereignty over the segment in question.

4. Treaty of 1967

The Treaty on Principles Governing the Activities of States in the Exploration and Use of Outer Space, including the Moon and Other Celestial Bodies, signed on 27 January 1967, cannot be considered as a final answer to the problem of the exploration and use of outer space, particularly since the international community is now calling in question all the terms of international law which were drawn up at a time when the developing countries could not count on adequate scientific advice and were thus not able to detect and assess the omissions, contradictions and inconsistencies in the texts, which were prepared with great ability by the industrialized Powers for their own benefit. 
There is no definition of outer space that is valid and satisfactory for the international community such as might be cited to support the argument that the geostationary orbit is included in outer space. The Legal Sub-committee of the United Nations Committee on the Peaceful Uses of Outer Space has been working for a long time on a definition of outer space but has not yet been able to reach agreement on the matter.

Therefore, it is imperative to arrive at a legal definition of outer space, since to apply the 1967 Treaty without one would merely be to ratify the presence of the states that are already using the geostationary orbit. In the name of the principle of non-appropriation by states, what was actually developed was a technological sharing-out of the orbit, which in the end simply comes down to national appropriation, and this must be denounced by the equatorial countries. Experience so far and the developments foreseeable in the years ahead show up the obvious gaps in the 1967 Treaty which force the equatorial states to take the position that the geostationary orbit is not covered by its provisions.

The lack of a definition of outer space in the 1967 Treaty, which has already been referred to, means that Article II can not apply to the geostationary orbit and therefore does not affect the rights of the equatorial states that have already ratified the Treaty.

\section{Diplomatic and political action}

While Article II of the aforementioned Treaty does not make an express exception for the synchronous geostationary orbit, as an integral part of the territory of equatorial states, the countries that have not ratified the Treaty should refrain from undertaking any steps to put into effect provisions whose legal invalidity has already been exposed.

The representatives of the equatorial countries attending the meeting in Bogota wish to make clear their position regarding the declarations by Colombia and Ecuador in the United Nations, affirming that they consider the geostationary orbit to be an integral part of their sovereign territory; this declaration is the historical background for the defence of the equatorial countries' sovereign rights. These countries will do their utmost to see that similar declarations are made in international agencies and to bring their international policies into line with the principles set forth in this document.

Signed in Bogota 3rd December 1976 by the Heads of Delegations.

(Signatures by representatives of Brazil, Colombia, Congo, Ecuador, Indonesia, Kenya, Uganda and Zaire) 